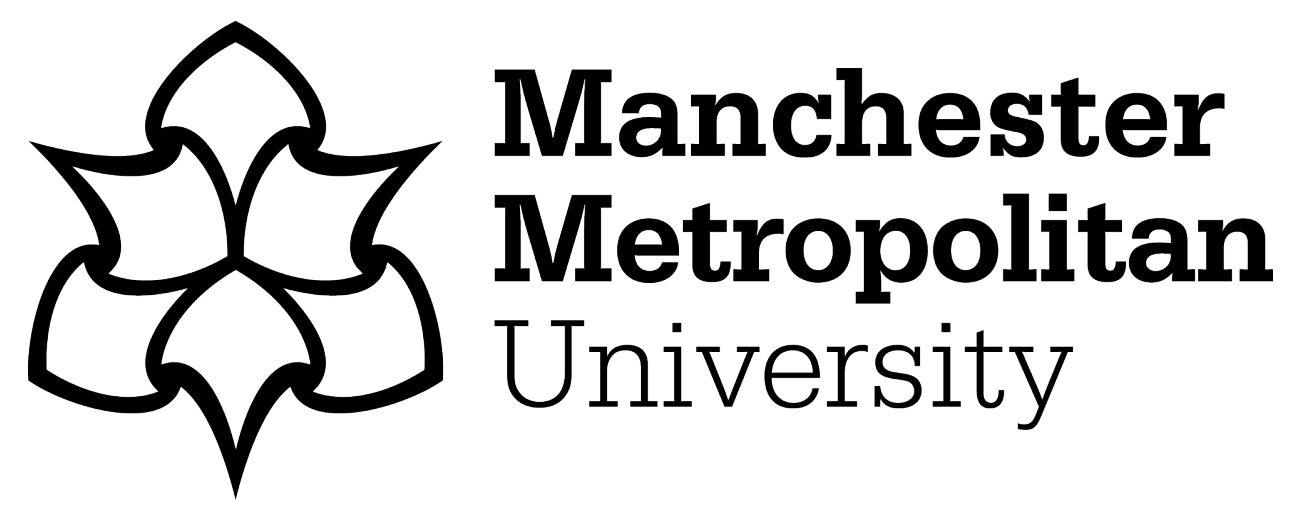

Vignesh, KR, Langley, SK, Gartshore, CJ, Moubaraki, B, Murray, KS and Rajaraman, G (2017) What Controls the Magnetic Exchange and Anisotropy in a Family of Tetranuclear \{Mn2IIMn2III\} Single-Molecule Magnets? Inorganic Chemistry, 56 (4). pp. 1932-1949. ISSN 0020-1669

Downloaded from: https://e-space.mmu.ac.uk/618280/

Version: Accepted Version

Publisher: American Chemical Society

DOI: https://doi.org/10.1021/acs.inorgchem.6b02527

Please cite the published version 


\title{
What Controls the Magnetic Exchange and Anisotropy in a Family of Tetranuclear $\left\{\mathrm{Mn}_{2}{ }^{\mathrm{II}} \mathrm{Mn}_{2}{ }^{\mathrm{III}}\right\}$ Single Molecule Magnets?
}

\author{
Kuduva R. Vignesh, ${ }^{\dagger}$ Stuart K. Langley, ${ }^{\prime}$ Christopher J Gartshore, ${ }^{\star}$ Boujemaa Moubaraki, ${ }^{\ddagger}$ Keith S. Murray, ${ }^{*}+$ and Gopalan \\ Rajaraman*, $\S$ \\ $\dagger$ IITB-Monash Research Academy, IIT Bombay, Mumbai-400076, India. \\ + School of Chemistry, Monash University, Clayton, Victoria-3800, Australia. \\ ! School of Science and the Environment, Chemistry Division, Manchester Metropolitan University, Manchester, UK. \\ $\S$ Department of Chemistry, Indian Institute of Technology Bombay, Mumbai-400076, India.
}

Supporting Information Place holder

\begin{abstract}
:
Twelve heterovalent, tetranuclear manganese(II/III) planar diamond or "butterfly" complexes, 1-12, have been synthesized, structurally characterized and their magnetic properties have been probed using experimental and theoretical techniques. The twelve structures are divided into two distinct "classes". Compounds $1-\mathbf{8}$ place the $\mathrm{Mn}(\mathrm{III}), S=2$, ions in the body positions of the "butterfly" metallic core, while the $\mathrm{Mn}(\mathrm{II}), S=5 / 2$, ions occupy the outer wing sites and are described as "Class 1 ". Compounds $\mathbf{9}-\mathbf{1 2}$ display the reverse arrangement of ions and are described as "Class 2". Direct current susceptibility measurements for $\mathbf{1}-\mathbf{1 2}$ reveal ground spin states ranging from $S=1$ to $S$ $=9$, with each complex displaying unique magnetic exchange parameters $(J)$. Alternating current susceptibility measurements found that that slow magnetic relaxation is observed for all complexes, except for $\mathbf{1 0}$ and 12, and display differing anisotropy barriers to magnetization reversal. Density functional theory calculations (DFT) have been performed to rationalize the experimental magnetic data. First we determined the magnitude of the magnetic exchange parameters for all complexes. Three exchange coupling constants ( $J_{\mathrm{bb}}, J_{\mathrm{wb}}$ and $\left.J_{\mathrm{ww}}\right) \mathrm{were}$ determined by DFT methods and were in good agreement with the experimental fits. It was found that the orientation of the Jahn-Teller axes and the $\mathrm{Mn}-\mathrm{Mn}$ distances play a pivotal role in determining the sign and strength of the $J_{b b}$ parameter. Further to this the interaction between the $\mathrm{Mn}(\mathrm{III})-\mathrm{d}_{\mathrm{z}}{ }^{2}$ and $\mathrm{Mn}(\mathrm{II})-\mathrm{d}_{\mathrm{z}}{ }^{2}$ orbitals control the sign and magnitude of the $J_{w b}$ parameter. Extensive magneto-structural correlations have been developed for the two classes of $\left\{\mathrm{Mn}_{2}{ }_{2} \mathrm{Mn}^{\mathrm{III}}{ }_{2}\right\}$ butterfly complexes by varying the $\mathrm{Mn}_{b}-\mathrm{O}$ distance, $\mathrm{Mn}_{\mathrm{w}}-\mathrm{O}$ distance, $\mathrm{Mn}_{\mathrm{b}}-\mathrm{O}-\mathrm{Mn}_{\mathrm{b}}$ angle $(\alpha), \mathrm{Mn}_{b}-\mathrm{O}-\mathrm{Mn}_{\mathrm{b}}-\mathrm{O}$ dihedral angle( $\mathrm{\gamma}$ ) and out-of-plane shift of the $\mathrm{Mn}_{\mathrm{w}}$ atoms $(\beta)$. The different $\mathrm{Mn}_{\mathrm{b}}-\mathrm{O}-\mathrm{Mn}_{\mathrm{b}}$ bond angles found for each complex is found have the greatest influence the sign and strength of the $J$ values reported. For the magnetic anisotropy the DFT calculations yielded a negative $D$ parameter for all complexes. Interestingly a larger negative $D$ value was observed for complexes $2,3,4$ and 6 compared to the other complexes. This enhancement in the magnitude of $D$ was correlated to the electron donating/withdrawing substituents and suggests a possible way to fine tune, the otherwise difficult to control, magnetic anisotropy in polynuclear Mn ion complexes.
\end{abstract}

\section{INTRODUCTION}

The structural and magnetic investigations of discrete mixed-valence manganese "butterfly" complexes possessing a $\left\{\mathrm{Mn}^{\mathrm{III}}{ }_{2} \mathrm{Mn}_{2}{ }_{2}\right\}$ magnetic core continues to attract interest, due to the fact these compounds were some of the first single-molecule magnets (SMMs) studied. ${ }^{1}$ These "butterfly" complexes however, are not limited to the above $\mathrm{Mn}(\mathrm{II}) / \mathrm{Mn}(\mathrm{III})$ ion type, with homo-valence $\left\{\mathrm{Mn}^{\mathrm{III}} 4\right\}$ and mixed-valence $\left\{\mathrm{Mn}^{\mathrm{III}}{ }_{3} \mathrm{Mn}^{\mathrm{IV}}\right\}$ magnetic cores also having been reported. ${ }^{2}$ Molecules that display SMM behavior reveal slow relaxation of the magnetization vector and magnetic hysteresis as a result of an energy barrier to spin inversion. ${ }^{3}$ In manganese based complexes this is due to a large spin ground state $(S)$, combined with an axial magnetic anisotropy, given by a negative zero-field splitting parameter (D). The energy barrier displays the relationship; $U=\mathrm{S}^{2}|D|$, and at low enough temperatures allows for the manipulation of the spin orientation by the magnetic field, resulting in several important potential applications. ${ }^{4}$ Mixed-valent $\left\{\mathrm{Mn}^{\mathrm{III}}{ }_{2} \mathrm{Mn}^{\mathrm{II}}{ }_{2}\right\}$ butterfly complexes often reveal the necessary requirements to observe SMM behavior, with the maximum possible ground spin state of $S=9$ being a common observation for this system. ${ }^{\mathbf{1 j}}$ These complexes also display a large enough anisotropy to block the magnetization vector along an easy axis, with $D$ values generally ranging from -0.15 to $-0.6 \mathrm{~cm}^{-1}$. The key attraction that makes these polynuclear complexes of particular interest to study is that it is possible, due to the relatively small nuclearity of these cluster types, to perform in-depth analyses of the magnetic interactions and of the SMM parameters. These are, therefore, excellent model complexes for the determination of the factors which can affect the SMM behavior and, ultimately, allow one to tune the parameters favorably. These "butterfly" complexes gain their name from the arrangement of their tetranuclear core, which contains four metal ions. Two are placed in the central "body", and two in the outer "wing" positions, with two oxygen ligands of $\mu_{3}-$

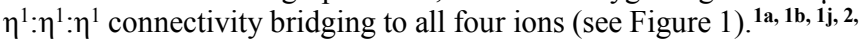
6 The $\mu_{3} \mathrm{O}$-atoms are typically $\mathrm{O}^{2-}$ or $\mathrm{OH}^{-}$, but can also be derived from alkoxide O-atoms. ${ }^{\mathbf{6}}$ It has also been shown that sulphide bridges can be used. ${ }^{6 e}$ These complexes can be homometallic, ${ }^{1 \mathbf{b}, 2 \mathbf{2 d}}$ or heterometallic with differing metal atoms located on the "wings" and "body" positions of the complex..$^{6 e}$ Due to the interest in SMMs, and manganese polynuclear complexes in particular, coupled with a near total lack of underlying theory, we have undertaken a combined experimental and density functional theoretical (DFT) approach focusing on twelve analogous mixed-valence manganese(II/III) butterfly complexes of formulae $\left[\mathrm{Mn}_{2} \mathrm{Mn}^{\mathrm{III}}{ }_{2}(\mathrm{hmp})_{6}\left(\mathrm{NO}_{3}\right)_{2}\left(\mathrm{H}_{2} \mathrm{O}\right)_{2}\right]\left(\mathrm{O}_{3} \mathrm{SC}_{6} \mathrm{H}_{4} \mathrm{CH}_{3}\right)_{2}(\mathbf{1})$, $\left[\mathrm{Mn}_{2} \mathrm{Mn}^{\mathrm{III}}{ }_{2}(\mathrm{hmp})_{6}\left(\mathrm{NO}_{3}\right)_{2}\left(\mathrm{O}_{3} \mathrm{SC}_{6} \mathrm{H}_{4} \mathrm{CH}_{3}\right)_{2}\right](\mathbf{2})$, $\left[\mathrm{Mn}_{2}{ }_{2} \mathrm{Mn}^{\mathrm{III}}{ }_{2}(\text { teaH })_{2}(\text { teaH })_{2}(\text { iso })_{2}\right]\left(\mathrm{NO}_{3}\right)_{2}(\mathbf{3})$, $\left.\left[\mathrm{Mn}_{2} \mathrm{Mn}^{\mathrm{III}}{ }_{2}(\text { teaH })_{2}(\text { teaH })_{2} \text { (pdca }\right)_{2}\right](4)$,

$\left.\left[\mathrm{Mn}_{2} \mathrm{Mn}^{\mathrm{III}}{ }_{2}(\text { teaH })_{2}(\text { teaH })_{2} \text { (piv) }\right)_{2}\right]$ (iso $)_{2}(\mathbf{5})$,

$\left.\left[\mathrm{Mn}_{2}{ }_{2} \mathrm{Mn}^{\mathrm{III}}{ }_{2} \text { (tea-4-nsa) }\right)_{2}(4-\mathrm{nsa})_{2}\left(\mathrm{H}_{2} \mathrm{O}\right)_{2}\right](\mathbf{6})$, $\left.\left[\mathrm{Mn}_{2}{ }_{2} \mathrm{Mn}^{\mathrm{III}}{ }_{2} \text { (tea-o-van }\right)_{2}(\text { o-van })_{2}(\mathrm{MeOH})_{2}\right](7)$, 
$\left.\left[\mathrm{Mn}_{2}{ }_{2} \mathrm{Mn}^{\mathrm{III}}{ }_{2} \text { (tea-o-van }\right)_{2}\left(\text { teaH }_{3}\right)_{2}\right]\left(\mathrm{NO}_{3}\right)_{2}(\mathbf{8})$, $\left.\left[\mathrm{Mn}_{2} \mathrm{Mn}^{\mathrm{III}} 2 \text { (teaH }\right)_{2}(\text { paa })_{4}\right]\left(\mathrm{NO}_{3}\right)_{2}(\mathbf{9})$, $\left.\left[\mathrm{Mn}_{2}{ }_{2} \mathrm{Mn}^{\mathrm{III}} 2 \text { (teaH }\right)_{2}\left(\mathrm{O}_{2} \mathrm{CPh}\right)_{4}(\mathrm{acac})_{2}\right](\mathbf{1 0})$, $\left[\mathrm{Mn}_{2}{ }_{2} \mathrm{Mn}^{\mathrm{III}}{ }_{2} \mathrm{Co}_{2} \mathrm{III}_{2}(\mathrm{teaH})_{4}(\mathrm{OMe})_{2}(\mathrm{acac})_{4}\right]\left(\mathrm{NO}_{3}\right)_{2}(\mathbf{1 1})$

$\left[\mathrm{Mn}_{2}{ }_{2} \mathrm{Mn}^{\mathrm{III}}{ }_{2}(\mathrm{teaH})_{2}(\mathrm{MeOH})_{4}(\mathrm{acac})_{4}\right]\left(\mathrm{ClO}_{4}\right)_{2}(\mathbf{1 2})$,

(where $\mathrm{hmpH}=2$-hydroxymethylpyridine, teaH $_{3}=$ triethanolamine, isoH $=$ isonicotinicacid, pdcaH $_{2}=3,4$-pyridinedicarboxylic acid, pivH $=$ pivalic acid, tea-4-nsaH $4=2-(\{2-[$ Bis-(2-hydroxy-ethyl $)-$ amino]-ethoxy $\}$-hydroxy-methyl)-4-nitro-phenol, 4-nsaH= 4-nitrosalicylaldehyde, tea-o-vanH $\mathrm{H}_{4}=2-(\{2-[\mathrm{Bis}-(2$-hydroxy-ethyl $)-$ amino]-ethoxy -hydroxy-methyl)-6-methoxy-phenol, o-vanH $=$ ortho-vanillin, paH $=2$-pyridylacetylacetamide, acacH $=$ acetylacetone). We have used these complexes, reported herein, to determine what structural features affect the key SMM parameters, $S$ and $D$. Nine of these complexes are newly synthesized $(\mathbf{1}-\mathbf{8}$ and $\mathbf{1 0})$, while three have been reported previously $(\mathbf{9}, 11$ and 12$) .{ }^{1 \mathbf{h}-\mathbf{j}}$ Due to the differences in $\mathrm{Mn}$ ion arrangement for $\mathbf{1}$ - 12 the compounds have been divided into two distinct "classes" to reflect these differences. Compounds $\mathbf{1}-\mathbf{8}$, which place the $\mathrm{Mn}(\mathrm{III}), S=2$, ions in the body positions of the butterfly metallic core, while the $\mathrm{Mn}(\mathrm{II}), S=5 / 2$, ions occupy the outer wing sites and are described as "Class 1". "Class 2" compounds consist of complexes $\mathbf{9 - 1 2}$ and display the reverse arrangement, with the $\mathrm{Mn}$ (II) ions in the body positions and the $\mathrm{Mn}$ (III) ions occupying the outer wing sites. Using single crystal X-ray diffraction, magnetic measurements and DFT calculations, a detailed analysis of the factors that affect the magnetic exchange and, ultimately, the SMM parameters $S$ and $D$, has been performed and the results are discussed herein.

\section{EXPERIMENTAL SECTION}

General Information. All reactions were carried out under aerobic conditions. Chemicals and solvents were obtained from commercial sources and used without further purification. Elemental analyses $(\mathrm{CHN})$ were carried out by Campbell Microanalytical Laboratory, University of Otago, Dunedin, New Zealand.

\section{Synthesis of metal complexes}

$\left[\mathrm{Mn}_{2} \mathrm{II} \mathrm{n}^{\mathrm{III}}{ }_{2}(\mathrm{hmp})_{6}\left(\mathrm{NO}_{3}\right)_{2}\left(\mathrm{H}_{2} \mathrm{O}\right)_{2}\right]\left(\mathrm{O}_{3} \mathrm{SC}_{6} \mathrm{H}_{4} \mathrm{CH}_{3}\right)_{2} \cdot \mathbf{2 M e C N} \cdot \mathbf{5} \mathrm{H}_{2} \mathrm{O}$

(1). $\mathrm{Mn}\left(\mathrm{NO}_{3}\right)_{2} \cdot 4 \mathrm{H}_{2} \mathrm{O}(0.25 \mathrm{~g}, 1.0 \mathrm{mmol})$ was dissolved in $\mathrm{MeOH}(20$ $\mathrm{mL})$, followed by the addition of 2-hydroxymethylpyridine $(0.1 \mathrm{~mL}$, $0.5 \mathrm{mmol})$, para-toluenesulfonic acid $(0.19 \mathrm{~g}, 1.0 \mathrm{mmol})$ and triethylamine $(0.28 \mathrm{~mL}, 2.0 \mathrm{mmol})$. This resulted in a deep brown solution which was stirred for three hours. After this time the solvent was removed leaving a brown oil. The oil was re-dissolved in $\mathrm{MeCN}$ and the solution was left to evaporate slowly. Within 1-week brown crystals of 1 had appeared, in approximate yield of $42 \%$ (crystalline product). Anal. Calculated (found) for 1: $\mathrm{Mn}_{4} \mathrm{C}_{54} \mathrm{H}_{70} \mathrm{O}_{25} \mathrm{~N}_{10} \mathrm{~S}_{2}: \mathrm{C}$, 42.03 (41.99); H, 4.57 (4.67); N, 9.08 (8.79).

$\left[\mathrm{Mn}_{2} \mathrm{Mn}^{\mathrm{III}}{ }_{2}(\mathrm{hmp})_{6}\left(\mathrm{NO}_{3}\right)_{2}\left(\mathrm{O}_{3} \mathrm{SC}_{6} \mathrm{H}_{4} \mathrm{CH}_{3}\right)_{2}\right] \cdot 2 \mathrm{MeCN}$ (2). The synthesis for 1 (above) was followed but a larger amount of para-toluenesulfonic acid was used $(0.76 \mathrm{~g}, 4.0 \mathrm{mmol})$. Brown crystals of 2 appeared within 1 week from slow evaporation of the MeCN solution, in approximate yield of $55 \%$ (crystalline product). Anal. Calculated (found) for 2: $\mathrm{Mn}_{4} \mathrm{C}_{54} \mathrm{H}_{56} \mathrm{O}_{18} \mathrm{~N}_{10} \mathrm{~S}_{2}: \mathrm{C}, 45.77$ (45.80); H, 3.98 (3.89); N, 9.89 (9.92).

$\left[\mathrm{Mn}_{2} \mathrm{Mn}^{I I I}{ }_{2}(\text { teaH })_{2}\left(\text { teaH }_{2}\right)_{2}(\text { iso })_{2}\right]\left(\mathrm{NO}_{3}\right)_{2} \cdot 2 \mathrm{MeOH}$ (3).

$\mathrm{Mn}\left(\mathrm{NO}_{3}\right)_{2} \cdot 4 \mathrm{H}_{2} \mathrm{O}(0.25 \mathrm{~g}, 1.0 \mathrm{mmol})$ was dissolved in $\mathrm{MeOH}(20$ $\mathrm{mL})$, followed by the addition of triethanolamine $(0.13 \mathrm{~mL}, 0.5$ $\mathrm{mmol})$, isonicotinic acid $(0.12 \mathrm{~g}, 1.0 \mathrm{mmol})$ and triethylamine $(0.55$ $\mathrm{mL}, 4.0 \mathrm{mmol}$ ), which resulted in a dark brown solution. This was stirred for 3 hours after which time the solvent was removed leaving a brown oil. The oil was re-dissolved in a $\mathrm{CH}_{2} \mathrm{Cl}_{2}: \mathrm{MeOH}(9: 1)$ mixture and, upon diffusing diethylether into the solution, brown crystals of $\mathbf{3}$ appeared within 1 day, in approximate yield of $78 \%$ (crystalline product). Anal. Calculated (found) for 3: $\mathrm{Mn}_{4} \mathrm{C}_{38} \mathrm{H}_{70} \mathrm{O}_{24} \mathrm{~N}_{8}: \mathrm{C}, 36.72$ (36.30); H, 5.68 (5.22); N, 9.02 (8.84).

$\left.\left[\mathrm{Mn}_{2} \mathrm{Mn}^{\mathrm{III}}{ }_{2}(\text { teaH })_{2}(\text { teaH })_{2}\right)_{2}(\mathrm{pdca})_{2}\right] \cdot 2 \mathrm{MeOH} \cdot 2 \mathrm{H}_{2} \mathrm{O}$ (4). The synthesis of 3 was followed but 3,4-pyridinedicarboxylic acid $(0.16 \mathrm{~g}$, $1.0 \mathrm{~mL}$ ) was used in place of isonicotinic acid. Brown crystals of 4 could be isolated from diffusion of diethylether into the methanolic solution, in approximate yield of $31 \%$ (crystalline product). Anal. Calculated (found) for 4: $\mathrm{Mn}_{4} \mathrm{C}_{40} \mathrm{H}_{72} \mathrm{O}_{24} \mathrm{~N}_{6}: \mathrm{C}, 38.72$ (38.50); H, 5.85 (5.52); N, 6.77 (6.34).

$\left.\left[\mathrm{Mn}_{2}^{I I} \mathrm{Mn}^{\mathrm{III}}{ }_{2}(\text { teaH })_{2}\left(\text { teaH }{ }_{2}\right)_{2} \text { (piv) }\right)_{2}\right](\text { iso })_{2} \cdot 2 \mathrm{MeCN}$ (5).

$\mathrm{Mn}\left(\mathrm{NO}_{3}\right)_{2} \cdot 4 \mathrm{H}_{2} \mathrm{O}(0.12 \mathrm{~g}, 0.5 \mathrm{mmol})$ was dissolved in $\mathrm{MeOH}(20$ $\mathrm{mL})$, followed by the addition of triethanolamine $(0.07 \mathrm{~mL}, 0.5$ $\mathrm{mmol})$, isonicotinic acid $(0.03 \mathrm{~mL}, 0.25 \mathrm{mmol}),\left[\mathrm{Mn}_{3} \mathrm{O}(\text { piv) })_{6}\right.$ (pyridine $\left.)_{3}\right]^{7}(0.1 \mathrm{~g}, 0.1 \mathrm{mmol})$ and triethylamine $(0.28 \mathrm{~mL}, 2.0 \mathrm{mmol})$. This resulted in a brown solution. The solution was stirred for 2 hours after which time the solvent was removed leaving a brown oil. The oil was re-dissolved in a MeCN:MeOH (9:1) mixture and upon slow evaporation of the solution brown crystals of 5 appeared within 1 - 2 days, in approximate yield of $54 \%$ (crystalline product). Anal. Calculated (found) for 5: $\mathrm{Mn}_{4} \mathrm{C}_{50} \mathrm{H}_{86} \mathrm{O}_{20} \mathrm{~N}_{8}: \mathrm{C}, 44.85$ (44.51); H, 6.47 (6.12); N, 4.37 (4.34).

\section{$\left[\mathrm{Mn}_{2} \mathrm{Mnn}_{2} \mathrm{MII}_{2}(\mathrm{tea}-4-\mathrm{nsa})_{2}(4-n \mathrm{sa})_{2}\left(\mathrm{H}_{2} \mathrm{O}\right)_{2}\right] \cdot 6 \mathrm{MeCN}(6)$.}

The synthesis of $\mathbf{3}$ was followed but 4-nitrosalicylaldehyde $(0.17 \mathrm{~g}$, $1.0 \mathrm{mmol}$ ) was used in place of isonicotinic acid. The resulting solution was stirred for 2 hours after which time the solvent was removed to give a brown solid. The solid was redissolved in $\mathrm{MeCN}$ and brown crystals of $\mathbf{6}$ appeared within 1 week, in approximate yield of $51 \%$ (crystalline product). Anal. Calculated (found) for 6: $\mathrm{Mn}_{4} \mathrm{C}_{52} \mathrm{H}_{62} \mathrm{O}_{24} \mathrm{~N}_{12}$ : C, 37.81 (37.80); H, $5.28(5.26) ; \mathrm{N}, 10.52$ (10.34). $\left[\mathrm{Mn}_{2} \mathrm{Mn}_{2} \mathrm{MI}_{2}(\text { tea-o-van })_{2}(\mathrm{o}-\mathrm{van})_{2}(\mathrm{MeOH})_{2}\right] \cdot 2 \mathrm{MeCN}$ (7). The synthesis of 3 was followed but ortho-vanillin $(0.45 \mathrm{~g}, 3 \mathrm{mmol})$ was used in place of isonicotinic acid. The resulting solution was stirred for 2 hours after which time the solvent was removed to give a brown solid. The solid was redissolved in a MeCN:MeOH (1:1) mixture and, upon diffusion of diethylether, brown crystals of 7 appeared within 1 week, in approximate yield of $43 \%$ (crystalline product). Anal. Calculated (found) for 7: $\mathrm{Mn}_{4} \mathrm{C}_{50} \mathrm{H}_{66} \mathrm{O}_{20} \mathrm{~N}_{4}: \mathrm{C}, 47.55$ (47.50); H, 5.27 (5.54); N, 4.44 (4.64).

$\left.\left[\mathrm{Mn}_{2}{ }_{2} \mathrm{Mn}^{I I I}{ }_{2} \text { (tea-o-van }\right)_{2}(\text { teaH })_{2}\right]\left(\mathrm{NO}_{3}\right)_{2} \cdot 2 \mathrm{MeCN}(8)$. The synthesis of 7 was followed but a smaller equivalent of ortho-vanillin $(0.15 \mathrm{~g}$, $1 \mathrm{mmol}$ ) was added. The resulting solution was stirred for 2 hours after which time the solvent was removed to give a brown solid. The solid was re-dissolved in $\mathrm{MeCN}$ and upon diffusion of diethylether into the solution brown crystals of $\mathbf{8}$ appeared within 1 week, in approximate yield of $49 \%$ (crystalline product). Anal. Calculated (found) for 8: $\mathrm{Mn}_{4} \mathrm{C}_{44} \mathrm{H}_{74} \mathrm{O}_{24} \mathrm{~N}_{8}: \mathrm{C}, 40.07$ (40.50); H, $5.66(5.72) ; \mathrm{N}$, $8.50(8.34)$.

$\left[\mathrm{Mn}_{2}{ }_{2} \mathrm{Mn}^{\text {III }}{ }_{2}(\text { teaH })_{2}\left(\mathrm{O}_{2} \mathrm{CPh}\right)_{4}(\text { acac })_{2}\right] \cdot \mathrm{MeCN}(10) . \mathrm{Mn}(\mathrm{acac})_{3}(0.36$ g, $1 \mathrm{mmol})$ was dissolved in $\mathrm{MeOH}(20 \mathrm{~mL})$, followed by the addition of triethanolamine $(0.13 \mathrm{~mL}, 1 \mathrm{mmol})$, benzoic acid $(0.1 \mathrm{~g}, 1.0$ mmol) and triethylamine $(0.55 \mathrm{~mL}, 4.0 \mathrm{mmol})$. This resulted in a brown solution. The solution was heated to reflux and stirred for 2 hours after which time the solvent was removed, to give a brown solid. The solid was re-dissolved in $\mathrm{MeCN}$ and, upon slow evaporation of the solution brown, crystals of $\mathbf{1 0}$ appeared within 1 week, in approximate yield of $62 \%$ (crystalline product). Calculated (found) for 10: $\mathrm{Mn}_{4} \mathrm{C}_{52} \mathrm{H}_{63} \mathrm{O}_{18} \mathrm{~N}_{3}$ : C, 50.46 (50.50); H, 5.13 (5.19); N, 3.40 (3.34). 
X-ray crystallography. X-ray measurements on $\mathbf{1}-\mathbf{8}$ and $\mathbf{1 0}$ were performed using a Bruker Smart Apex X8 diffractometer with Mo $\mathrm{K} \alpha$ radiation. The data collection and integration were performed within SMART and SAINT+ software programs, and corrected for absorption using the Bruker SADABS program. Compounds $1-\mathbf{8}$ and 10 were all solved by direct methods (SHELXS-97) ${ }^{\mathbf{8}}$, and refined (SHELXL-97) ${ }^{9}$ by full least matrix least-squares on all $F^{2}$ data. ${ }^{10}$ Crystallographic data and refinement parameters for $\mathbf{1}-\mathbf{8}$ and $\mathbf{1 0}$ are summarized in Table ST1. Crystallographic details are available in the Supporting Information (SI) in CIF format. CCDC numbers of $\mathbf{1}$ $-\mathbf{8}$ and $\mathbf{1 0}$ are 1483120-1483128. These data can be obtained free of charge from the Cambridge Crystallographic Data Center viawww.ccdc.cam.ac.uk/data request/cif.

Magnetic Measurements. The magnetic susceptibility measurements were carried out on a Quantum Design SQUID magnetometer MPMS-XL 7 operating between 1.8 and $300 \mathrm{~K}$ for dc-applied fields ranging from $0-5 \mathrm{~T}$. Microcrystalline samples were dispersed in Vaseline in order to avoid torquing of the crystallites. The sample mulls were contained in a calibrated gelatine capsule held at the centre of a drinking straw that was fixed at the end of the sample rod. Alternating current (ac) susceptibilities were carried out under an oscillating ac field of $3.5 \mathrm{Oe}$ and frequencies ranging from 0.1 to 1500 $\mathrm{Hz}$.

\section{Computational Details}

The energies of four spin configurations for $\mathbf{1}-\mathbf{1 2}$ are computed to extract the exchange interactions (see ESI for details). ${ }^{11}$ The computed spin configurations for $\mathbf{1} \mathbf{- 1 2}$ are given in the ESI (Table ST7). The exchange coupling constants have been calculated using the Broken Symmetry (BS) approach developed by Noodleman. ${ }^{12}$ This method has been employed previously to compute good numerical estimates of exchange interactions in numerous polynuclear complexes. ${ }^{\mathbf{1 3}}$ Here all the density functional theory (DFT) calculations were performed using the B3LYP functional ${ }^{14}$ with Ahlrich's ${ }^{15}$ triple- $\zeta$-quality basis set. All the calculations have been performed with the Gaussian 09 suite of programs. ${ }^{16}$ The $\mathrm{PHI}^{17}$ program was used for simulating the magnetic susceptibilities. The following spin Hamiltonian was used to calculate the magnetic exchange interactions.

$$
\begin{array}{r}
\widehat{H}=-\left[2 J_{w b}\left(S_{M n 1} S_{M n 3}+S_{M n 1} S_{M n 4}+S_{M n 2} S_{M n 3}+S_{M n 2} S_{M n 4}\right)\right. \\
\left.+2 J_{b b}\left(S_{M n 1} S_{M n 2}\right)+2 J_{w w}\left(S_{M n 3} S_{M n 4}\right)\right] E q 1
\end{array}
$$

The zero-field splitting (ZFS) parameter has also been computed for complexes possessing an $S_{\mathrm{gs}}=9$ ground state using the ORCA program suite. ${ }^{18}$ The ZFS parameters are computed using DFT calculations, where the spin-orbit coupling operators are represented by an effective one electron operator using the spin-orbit mean field (SOMF) method as implemented in ORCA using the B3LYP functional. ${ }^{18}$ We have used the coupled perturbed (CP) SOC approach to evaluate the spin-orbit contribution to $D\left(D_{\mathrm{SOC}}\right)$. The spin-spin contribution $\left(D_{S S}\right)$ was estimated by using the unrestricted natural orbital approach. Further, to improve the accuracy of the estimated $D$ values, relativistic corrections were performed using the DKH method. Although $a b$ initio CASSCF/PT2 calculations have proven to yield accurate estimates of $D$ values, ${ }^{19}$ this methodology cannot be employed here due to the large size of the $\left\{\mathrm{Mn}_{4}\right\}$ complexes.

\section{RESULTS AND DISCUSSION}

\section{Synthesis}

The targeted syntheses of the $\left\{\mathrm{Mn}_{2}{ }_{2} \mathrm{Mn}^{\mathrm{III}}{ }_{2}\right\}$ butterfly complexes reported in this work employed the use of two primary ligands. The first, triethanolamine (teaH $\mathrm{H}_{3}$ ) was utilized due to previous literature reports of homometallic $3 \mathrm{~d}$ and heterometallic $3 \mathrm{~d}-3 \mathrm{~d}$ and $3 \mathrm{~d}-4 \mathrm{f}$ tetranuclear butterfly complexes incorporating this ligand. ${ }^{\mathbf{1 h}-\mathbf{j}, \mathbf{1} \mathbf{u}, \mathbf{2 0}} \mathrm{A} \mathrm{sec}-$ ond ligand, which also revealed a propensity for the stabilization of the butterfly metal core topology is 2-hydroxymethylpyridine $(\mathrm{hmpH}) .{ }^{1 \mathbf{s}, 1 \mathbf{1 t}, \mathbf{6 g}}$ Using these two ligands and upon selection of an appropriate co-ligand it was found that one could easily isolate a range of new mixed-valent $\mathrm{Mn}$ (II/III) butterfly compounds.

When using $\mathrm{hmpH}$, the co-ligand in question was para-toluene sulfonic acid (1 and 2). Using teaH $\mathrm{H}_{3}$, three co-ligands were employed which were of the carboxylic acid (3-5) and salicylaldehyde type (6 - 8). Interestingly, the combination of alcohol and aldehyde groups in basic conditions resulted in the in-situ formation of a hemiacetal functional group and the synthesis of two new ligands. This is observed in complexes $\mathbf{6}-\mathbf{8}$, and it was found that these ligands have not been previously used in the synthesis of polynuclear complexes. The molecular structure of these ligands (tea-4-nsa- and tea-o-van ${ }^{4-}$ ), in their coordinated form are shown in Scheme 1. The ligands are multidentate and will be useful for the syntheses of polynuclear clusters in future studies. The third type of co-ligand utilized are $\beta$ diketonates and resulted in complexes $9-\mathbf{1 2}$.

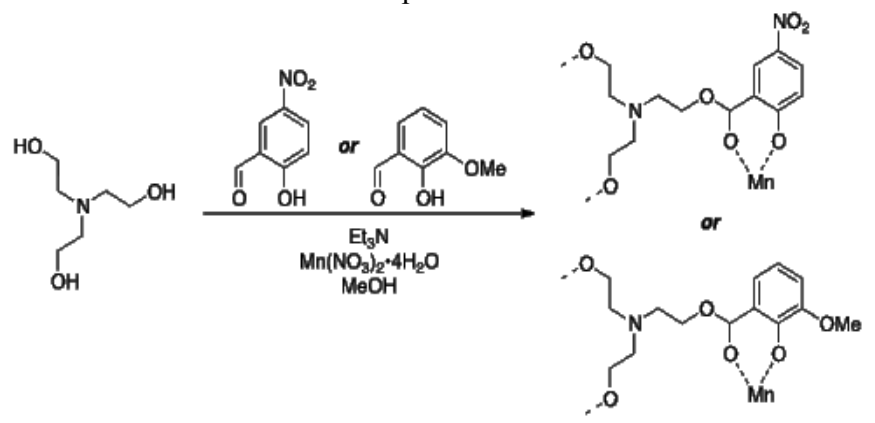

Scheme 1. The in-situ formation of the coordinated 2-(\{2-[Bis-(2hydroxy-ethyl)-amino]-ethoxy $\}$-hydroxy-methyl)-4-nitro-phenol; tea-4-nsaH 4 (top) and 2-(\{2-[Bis-(2-hydroxy-ethyl)-amino]-ethoxy $\}$ hydroxy-methyl)-6-methoxy-phenol, tea-o-vanH 4 (bottom), from teaH $_{3}$ and the appropriate salicylaldehyde.

\section{Structural descriptions}

The molecular structures of $\mathbf{1} \mathbf{- 1 2}$ were determined by single crystal $\mathrm{X}$-ray diffraction measurements, which revealed mixed-valent tetranuclear manganese (II/III) complexes. As discussed above, all twelve complexes display a butterfly (or planar-diamond) metallic core arrangement. It was found that the twelve complexes could be divided into two groups denoted as "Class 1" and "Class 2". The molecular structures of $\mathbf{1}$ and $\mathbf{9}$ are shown in Figure 1 as representative examples of Class 1 (top) and Class 2 (bottom). The molecular structure of $\mathbf{2}-\mathbf{8}$ and $\mathbf{1 0}-\mathbf{1 2}$ are given in Figures SF1 and SF2. The two distinct structural groups are classified with respect to the metal ions. Class 1 compounds, $\mathbf{1}-\mathbf{8}$, reveal that the Mn(III) ions are found in the central body positions of the "butterfly" while the Mn(II) ions occupy the outer wing sites (Figure 1a). Class 2 complexes, 9-12, display the reverse oxidation state arrangement (Figure 1b). The oxidation states of the Mn ions were easily determined via bond length parameters, structural distortions and bond valence sum $^{21}$ calculations (Table ST2). For the sake of brevity, a general description relating to all complexes will be given. It is observed that two $\mu_{3} \mathrm{O}-$ atoms bridge the two body $\mathrm{Mn}$ ions to an outer $\mathrm{Mn}$ wing site in all cases. The $\mathrm{O}$-atom is derived from a deprotonated arm of the aminepolyalcohol or the hmp- ligand. The complexes are further stabilized around the periphery of the core by $\mu_{2} \mathrm{O}$-atoms that bridge a central 
$\mathrm{Mn}$ ion to an outer Mn site. These connections are derived from the amine-polyalcohol ligand or the hmp- ligands.

Table 1. Description of the bridging ligands, average $\mathrm{Mn} \cdots \mathrm{Mn}$ distances, Mn-O-Mn angles and related $J_{\mathrm{wb}}$ and $J_{\mathrm{bb}}$ pathways in complexes 1-12.

\begin{tabular}{|c|c|c|c|c|c|c|}
\hline \multirow{2}{*}{$\begin{array}{l}\text { Co } \\
\text { mp } \\
\text { lex }\end{array}$} & \multicolumn{2}{|c|}{ Bridging ligands } & \multicolumn{2}{|c|}{$\mathrm{d}(\mathrm{Mn}-\mathrm{Mn}) \AA$} & \multicolumn{2}{|c|}{ Mn-O-Mn angle $\left(^{\circ}\right)$} \\
\hline & $J_{\mathrm{wb}}$ & $J_{\mathrm{bb}}$ & $J_{\mathrm{wb}}$ & $J_{\mathrm{bb}}$ & $J_{\mathrm{wb}}$ & $J_{\mathrm{bb}}$ \\
\hline 1 & $\begin{array}{l}\mu_{3}-\mathrm{O}\left\{\mathrm{hmp}^{-}\right\} \\
\mu_{2}-\mathrm{O}\left\{\mathrm{hmp}^{-}\right\}\end{array}$ & $\mu_{3}-\mathrm{O}\left\{\mathrm{hmp}^{-}\right\}$ & $\begin{array}{l}3.357, \\
3.273\end{array}$ & 3.227 & $\begin{array}{l}95.9,100.9, \\
106.7,109.7\end{array}$ & 99.4 \\
\hline 2 & $\begin{array}{l}\mu_{3}-\mathrm{O}\left\{\mathrm{hmp}^{-}\right\} \\
\mu_{2}-\mathrm{O}\left\{\mathrm{hmp}^{-}\right\}\end{array}$ & $\mu_{3}-\mathrm{O}\left\{\mathrm{hmp}^{-}\right\}$ & $\begin{array}{l}3.412, \\
3.297\end{array}$ & 3.259 & $\begin{array}{c}99.6,94.6, \\
108.8,112.4\end{array}$ & 100.2 \\
\hline 3 & $\begin{array}{l}\mu_{3}-\mathrm{O}\left\{\text { teaH }^{2-}\right\} \\
\mu_{2}-\mathrm{O}\left\{\text { teaH }_{2}^{-}\right\}\end{array}$ & $\mu_{3}-\mathrm{O}\left\{\right.$ teaH $\left.^{2-}\right\}$ & $\begin{array}{l}3.357, \\
3.213\end{array}$ & 3.195 & $\begin{array}{l}89.8,102.7, \\
107.4,108.9\end{array}$ & 99.3 \\
\hline 4 & $\begin{array}{l}\mu_{3}-\mathrm{O}\left\{\text { teaH }^{2-}\right\} \\
\mu_{2}-\mathrm{O}\left\{\text { tea } \mathrm{H}_{2}^{-}\right\}\end{array}$ & $\mu_{3}-\mathrm{O}\{\mathrm{te}$ & $\begin{array}{l}3.328, \\
3.234\end{array}$ & 3.136 & $\begin{array}{l}91.6,103.7, \\
107.7,106.8\end{array}$ & 96.4 \\
\hline 5 & $\begin{array}{l}\mu_{3}-\mathrm{O}\left\{\mathrm{teaH}^{2-}\right\} \\
\mu_{2}-\mathrm{O}\left\{\mathrm{teaH}_{2}^{-}\right\}\end{array}$ & $\mu_{3}-\mathrm{C}$ & $\begin{array}{l}3.320, \\
3.337\end{array}$ & 3.152 & $\begin{array}{l}89.0,102.9, \\
104.6,107.9\end{array}$ & 97.5 \\
\hline 6 & $\begin{array}{c}\mu_{3}-\mathrm{O}\{\text { tea- } 4- \\
\left.\mathrm{nsa}^{3-}\right\}\end{array}$ & $\begin{array}{c}\mu_{3}-\mathrm{O}\{\text { tea- } 4- \\
\left.\mathrm{nsa}^{3-}\right\}\end{array}$ & 3.335 & 3.201 & $\begin{array}{c}93.1,99.9 \\
109.2,112.7\end{array}$ & 99.9 \\
\hline 7 & $\begin{array}{c}\mu_{3}-\mathrm{O}\{\text { tea-o- } \\
\left.\operatorname{van}^{3-}\right\}\end{array}$ & $\begin{array}{c}\mu_{3}-\mathrm{O}\{\text { tea-o- } \\
\left.\operatorname{van}^{3-}\right\}\end{array}$ & $\begin{array}{l}3.251, \\
3.268\end{array}$ & 3.257 & $\begin{array}{c}93.4,99.8, \\
105.7,108.8\end{array}$ & 101.1 \\
\hline 8 & $\begin{array}{c}\mu_{3}-\mathrm{O}\{\text { tea-o- } \\
\left.\operatorname{van}^{3-}\right\}\end{array}$ & $\begin{array}{c}\mu_{3}-\mathrm{O}\{\text { tea-o- } \\
\left.\operatorname{van}^{3-}\right\}\end{array}$ & $\begin{array}{l}3.385, \\
3.388\end{array}$ & 3.217 & $\begin{array}{c}\text { 92.3,99.3, } \\
110.0,113.3\end{array}$ & 100.1 \\
\hline 9 & $\begin{array}{c}\mu_{3}-\mathrm{O}\left\{\text { teaH }^{2-}\right\} \\
\mu_{2}-\mathrm{O}\left\{\mathrm{paa}^{-}\right\}\end{array}$ & $\mu_{3}-\mathrm{O}\left\{\right.$ teaH $\left.^{2-}\right\}$ & $\begin{array}{l}3.306, \\
3.316\end{array}$ & 3.628 & $\begin{array}{l}97.0,104.4, \\
97.6,111.1\end{array}$ & 100.9 \\
\hline 10 & $\mu_{3}-\mathrm{O}\left\{\right.$ teaH $\left.^{2-}\right\}$ & $\mu_{3}-\mathrm{O}\left\{\right.$ teaH $\left.^{2-}\right\}$ & $\begin{array}{l}3.215, \\
3.568\end{array}$ & 3.444 & $\begin{array}{c}91.3,128.4 \\
110.8\end{array}$ & 95.7 \\
\hline 11 & $\begin{array}{c}\mu_{3}-\mathrm{O}\left\{\mathrm{teaH}^{2-}\right\} \\
\mu_{2}-\mathrm{MeO}^{-}\end{array}$ & $\mu_{3}-\mathrm{O}\left\{\mathrm{tea}^{2-}\right\}$ & $\begin{array}{l}3.272, \\
3.322\end{array}$ & 3.625 & $\begin{array}{l}99.9,102.7 \text {, } \\
94.4,105.9\end{array}$ & 102.0 \\
\hline 12 & $\begin{array}{c}\mu_{3}-\mathrm{O}\left\{\mathrm{teaH}^{2-}\right\} \\
\mu_{2}-\mathrm{O}\left\{\mathrm{acac}^{-}\right\}\end{array}$ & $\mu_{3}-\mathrm{O}\left\{\mathrm{tea}^{2-}\right\}$ & $\begin{array}{l}3.384, \\
3.390\end{array}$ & 3.728 & $\begin{array}{l}93.5,110.8, \\
98.0,115.0\end{array}$ & 99.9 \\
\hline
\end{tabular}

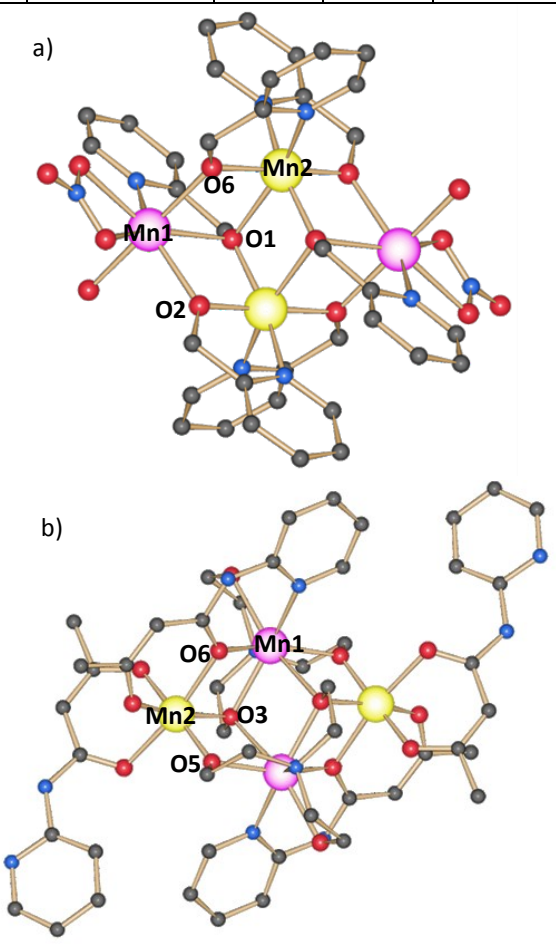

Figure 1. The molecular structure of compounds a) 1 (Class 1) and b) 9 (Class 2). The $\mathrm{H}$-atoms and solvent molecules are omitted for clarity. Colour scheme; $\mathrm{Mn}^{\mathrm{III}}$, yellow; $\mathrm{Mn}^{\mathrm{II}}$, pink; O, red; N, blue; $\mathrm{C}$, grey.
The ligands are also found to bridge the $\mathrm{Mn}$ (II) and $\mathrm{Mn}$ (III) ions (carboxylates) and both bridge and chelate ([ $\beta$-diketonates $]^{-},[\mathrm{hmp}]^{-}$, $[\text { teaH }]^{2-}$, [p-tol $]^{-}$), capping the coordination sites. The Mn(III) ions are six coordinate in all complexes, with Jahn-Teller axially distorted octahedral geometries. The Mn(II) ions in complexes 6, 7 and $\mathbf{1 0}$ are six coordinate with distorted octahedral geometries, while the $\mathrm{Mn}$ (II) ions for the remaining nine complexes are seven coordinate, with pentagonal bipyramidal $(\mathbf{1}-\mathbf{5}$ and $\mathbf{8})$ and capped octahedral $(\mathbf{9}, 11$ and 12) geometries. We note that the two long Mn-O contacts $(\sim 2.6$ $\AA$ ) for compounds $\mathbf{1 0}$ and $\mathbf{1 2}$ are considered as weak bonds. Tables 1 and ST3 contain selected structural parameters and how they relate to the magnetic exchange $(J)$ pathways. From the structural data the first notable observation is the role the co-ligand plays in influencing the position of the metal ions in the butterfly motif. Class 1 compounds are obtained when using carboxylate and salicylaldehyde coligands with teaH $\mathrm{H}_{3}$, or tosylate co-ligands with $\mathrm{hmpH}$. However, when $\beta$-diketone ligands are used in conjunction with tea $\mathrm{H}_{3}$, Class 2 complexes are isolated exclusively, even in the presence of a carboxylate ligand, as seen for 10. A second structural observation reveals that compounds $\mathbf{3}$ and $\mathbf{4}$ can conceivably be used as SMM nodes (see magnetic properties, vide infra) in the formation of metal-organic frameworks, due to the non-coordinating 3- and 4-pyridyl groups present (Figure SF1b and SF1c). Several 1-, 2- and 3-D networks based on $\left\{\mathrm{Mn}_{4}\right\}$ butterfly complexes have previously been reported. ${ }^{5}$ The packing motifs in the crystals of complexes $\mathbf{1}-\mathbf{1 2}$ have been analyzed (see Figure SF3-SF6). For 1, 3, 5, 10 and 11, we observe intermolecular H-bonding interactions which form 1-D chains of $\left\{\mathrm{Mn}_{4}\right\}$ moieties throughout the crystal. For $\mathbf{1}$ these chains are formed via interactions between the $\mathrm{O}$-atoms of the sulphonate groups and coordinated and non-coordinated water molecules (Figure SF3 (a)). For 3 two types of H-bonded interactions are found. The first is a single $\mathrm{H}$-bond between the $\mathrm{N}$-atom of the pyridyl ring and a $\mathrm{O}-\mathrm{H}$ of a (teaH $)^{-}$ligand. The second reveals three $\mathrm{H}$-bonds between multiple groups - a O-H of a (teaH) $)^{2-}$ ligand, a solvent $\mathrm{MeOH}$, a nitrate and a $\mathrm{O}-\mathrm{H}$ of a (teaH $\left.)_{2}\right)^{-}$ligand (Figure SF3 (c)). For 5 the H-bonded chains are a result of a O-H (teaH) $)^{2}$-interaction from one $\left\{\mathrm{Mn}_{4}\right\}$ moiety with the $\mathrm{N}$-atom of the pyridyl ring of the non-coordinating isonicotinate molecule and the $\mathrm{O}-\mathrm{H}\left(\mathrm{teaH}_{2}\right)^{-}$of an adjacent $\left\{\mathrm{Mn}_{4}\right\}$ unit with the carboxylate group of the same isonicotinate ligand (Figure SF4 (b)). For 10 intermolecular $\mathrm{H}$-bonds are formed between the non-coordinating O-H group of a (teaH) $)^{2-l i g a n d ~ a n d ~ a ~ c a r b o x y l a t e ~ O-a t o m ~(F i g u r e ~ S F 6 ~}$ (a)). For 11 two H-bonds are formed between the O-H of a (teaH $)^{2-}$ ligand, a nitrate and a water molecule (Figure SF6 (b)). For complexes 4 and 9 intermolecular H-bonding interactions result in 2-D sheets throughout the crystal (Figure SF4 (a) and SF5 (c), respectively). For 2, 6 and 7 offset $\pi-\pi$ interactions are found between the hmp ligands (Figure SF3 (b)), 4-nsa ligands (Figure SF4 c)) and ovan ligands (Figure SF5 a)) resulting in 1-D chains. Finally, no significant intermolecular interactions are observed for $\mathbf{8}$ and $\mathbf{1 2}$.

\section{Magnetic Susceptibility Studies:}

\section{DC susceptibility and magnetization studies}

Direct current (dc) magnetic susceptibility measurements were performed on polycrystalline samples of $\mathbf{1 - 1 2}$ in the temperature range 
$2-300 \mathrm{~K}$, using an applied magnetic field of $1 \mathrm{~T}$ (Figure 3). Isothermal magnetization plots were also recorded in fields between $0-5 \mathrm{~T}$ (Figure 4). A large variation in the temperature dependent behavior is observed for the $\chi_{M} T$ product for some of the compounds $\mathbf{1}-\mathbf{1 2}$. This observation is due to different exchange parameters and spin state energy levels for each analogue (vide infra), and thus this family of compounds provide an ideal vehicle for probing the reasons that can cause such differences. If we focus on the experimental plots in Fig. 3, we see that compounds 1, 2, 3, 4, 6 and 11 show that the $\chi_{M} T$ values of $\sim 15.5 \mathrm{~cm}^{3} \mathrm{~K} \mathrm{~mol}^{-1}$ at $300 \mathrm{~K}$ are slightly greater than that expected for the uncoupled value for two $S=2$ (Mn(III)) and two S $=5 / 2(\mathrm{Mn}(\mathrm{II}))$ centers of $14.75 \mathrm{~cm}^{3} \mathrm{~K} \mathrm{~mol}^{-1}$. On decreasing the temperature, the $\chi_{M} T$ values increase gradually down to $\sim 70 \mathrm{~K}$, then more rapidly to reach a sharp maximum $\left(\sim 33-37 \mathrm{~cm}^{3} \mathrm{~K} \mathrm{~mol}^{-1}\right.$ at $\left.\sim 11 \mathrm{~K}\right)$, before rapidly decreasing at the lowest temperatures $(>10 \mathrm{~K})$. These profiles are indicative of dominant ferromagnetic cluster exchange interactions.

If ferromagnetic coupling is observed for all spins, resulting in a $S_{\mathrm{gs}}$ $=9$ ground state, then the predicted $\chi_{M} T$ value of this state is $45 \mathrm{~cm}^{3}$ $\mathrm{K} \mathrm{mol}^{-1}(g=2)$. The observed maxima are, however, found to be lower than this value due to a combination of zero field splitting, Zeeman level depopulations effects and intercluster antiferromagnetic coupling, the latter two leading to the rapid decrease below the maximum. The $\chi M T_{\max }$ values are coincidentally close to the value expected for an isolated $S=8$ state of $36 \mathrm{~cm}^{3} \mathrm{~K} \mathrm{~mol}^{-1}$. The magnetization isotherms (Figure 4 and Figures SF 19 - 21; ESI) are also indicative of zero field splitting (vide infra). Previous work on $\left\{\mathrm{Mn}_{2}{ }_{2} \mathrm{Mn}^{\mathrm{III}}{ }_{2}\right\}$ clusters yielded similar $\chi_{M} T(\mathrm{~T})$ plots to those found here, arising from a $S_{\mathrm{gs}}=9$ ground state, often close in energy to higher lying $S=8$ and other spin states of lower value. ${ }^{\mathbf{1 a}, \mathbf{1 b}, \mathbf{1 h}-\mathbf{r}, \mathbf{2}, \mathbf{6 a - e}}$

For compounds 5 and 9 the $\chi_{M} T_{\max }$ values are found to be lower, at $\sim 20-22 \mathrm{~cm}^{3} \mathrm{~K} \mathrm{~mol}^{-1}$ and even lower for 7 and 8 , with values of $\sim 16.5 \mathrm{~cm}^{3} \mathrm{~K} \mathrm{~mol}^{-1}$, suggestive of antiferromagnetic contributions to the exchange coupling. Complexes $\mathbf{1 0}$ and $\mathbf{1 2}$ reveal the absence of any maximum in $\chi_{M} T$, with a gradual decrease of $\chi_{M} T$ between 300 and $50 \mathrm{~K}$, followed by a more rapid decrease down to $2 \mathrm{~K}$, reaching $\sim 0 \mathrm{~cm}^{3} \mathrm{~K} \mathrm{~mol}^{-1}$, indicative of antiferromagnetic contributions to the exchange coupling. The $M(H)$ isotherms for 7 and 8 (Figure SF20) and 12 (Figure 4) support antiferromagnetic coupling by their linearlike shapes and low $M$ values. They also suggest the presence of nearby non-zero spin states that are thermally populated at progressively higher dc fields.

Fitting of the experimental magnetic data in order to extract the nature and the magnitude of the magnetic exchange interactions $(J)$ within each complex was performed using the PHI program. ${ }^{17}$ It is often found that only two $J$ values - $J_{\mathrm{bb}}$ and $J_{\mathrm{wb}}$ (Figure 2) are generally reported due to the complications of performing fits of experimental data with multiple $J$ 's and thus the $J_{w w}$ interaction has been set at zero in this study. Since there are four $J_{w b}$ and only one $J_{b b}$, we found that the fit is insensitive to the $J_{b b}$ value. Thus we have fixed the $J_{b b}$ values to that calculated from DFT and extracted the $J_{w b}$ and $D$ parameters from the fit. The results of fitting the experimental data are presented in Table 2, left columns. It is found that the $70-300 \mathrm{~K}$ temperature region is the most sensitive to the $J$ values, while at lower temperatures the $\chi_{M} T$ value is most sensitive to the zero field splitting and inter-molecular cluster coupling. We note that when using DFT all three exchange parameters (Equation 1) are explicitly calculated (vide infra). The cross comparison of experimental and calculated (DFT) $J$ values is explained in the theoretical studies section below. Equation 2 is the Hamiltonian used to fit the magnetic data to determine $J$ and $D(g=2.0)$ for each complex. For comparison we have listed the $J, D$ and $S$ values for literature reported butterfly $\left\{\mathrm{Mn}^{\mathrm{III}}{ }_{2} \mathrm{Mn}^{\mathrm{II}} 2\right\}$ complexes in Table 3 .

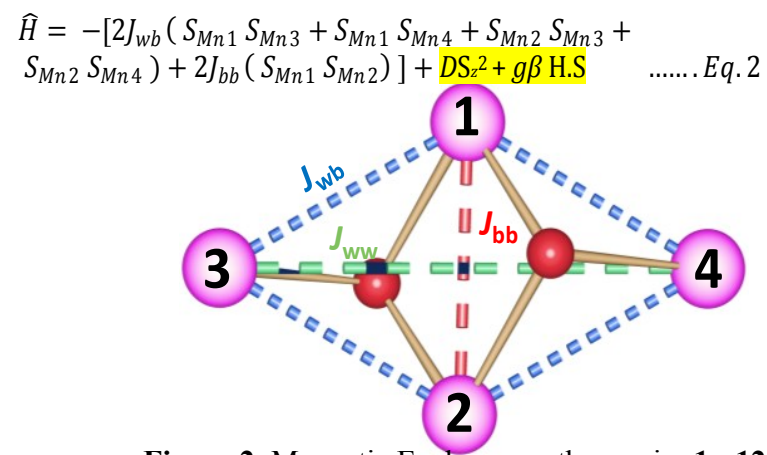

Figure 2. Magnetic Exchange pathways in $\mathbf{1}$ - 12.

Table 2: Experimentally fitted and DFT calculated exchange coupling constants ( $J$ values) for $\mathbf{1} \mathbf{- 1 2}$.

\begin{tabular}{|c|c|c|c|c|c|c|c|c|}
\hline \multirow{3}{*}{$\begin{array}{c}\text { Co } \\
\text { mpl } \\
\text { ex }\end{array}$} & \multicolumn{4}{|c|}{$\begin{array}{l}\text { Fits to experimental data us- } \\
\quad \text { ing } \mathrm{PHI}^{17} ; g=2.0\end{array}$} & \multicolumn{4}{|c|}{$\begin{array}{l}\text { DFT calculated } J \text { values and } \\
\text { spin ground state }\end{array}$} \\
\hline & \multicolumn{2}{|c|}{$J\left(\mathrm{~cm}^{-1}\right)$} & \multirow{2}{*}{$\begin{array}{c}D \\
\left(\mathrm{~cm}^{-1}\right)\end{array}$} & \multirow[b]{2}{*}{$S_{\mathrm{gs}}$} & \multicolumn{3}{|c|}{$J\left(\mathrm{~cm}^{-1}\right)$} & \multirow[b]{2}{*}{$S_{\mathrm{gs}}$} \\
\hline & $J_{\mathrm{wb}}$ & $J_{\mathrm{bb}}$ & & & $J_{\mathrm{wb}}$ & $J_{\mathrm{bb}}$ & $J_{\mathrm{ww}}$ & \\
\hline & \multicolumn{8}{|c|}{ Class 1} \\
\hline 1 & 1.87 & 0.01 & -0.33 & 9 & 1.24 & 0.01 & -0.01 & 9 \\
\hline 2 & 1.39 & -0.06 & -0.37 & 9 & 1.37 & -0.06 & -0.03 & 9 \\
\hline 3 & 0.66 & 2.32 & -0.34 & 9 & 0.37 & 2.32 & -0.08 & 9 \\
\hline 4 & 0.88 & 2.06 & -0.32 & 9 & 0.49 & 2.06 & -0.03 & 9 \\
\hline 5 & 0.02 & 2.22 & -0.43 & 9 & 0.15 & 2.22 & -0.06 & 9 \\
\hline 6 & 0.47 & 0.66 & -0.32 & 9 & 0.31 & 0.66 & -0.03 & 9 \\
\hline 7 & -0.42 & 0.26 & -0.01 & 1 & 0.24 & 0.26 & -0.02 & 9 \\
\hline \multirow[t]{2}{*}{8} & -0.46 & 0.27 & 0.01 & 1 & 0.18 & 0.27 & -0.03 & 9 \\
\hline & \multicolumn{8}{|c|}{ Class 2} \\
\hline 9 & 0.28 & -0.13 & -0.35 & 9 & 0.47 & -0.13 & -0.02 & 9 \\
\hline 10 & 0.05 & -0.86 & -0.01 & $1-4$ & 0.32 & -0.86 & 0.08 & 3 \\
\hline 11 & 1.15 & -0.03 & -0.33 & 9 & 1.08 & -0.03 & -0.03 & 9 \\
\hline 12 & -0.51 & 0.02 & 0.003 & 1 & -0.45 & 0.02 & 0.001 & 1 \\
\hline
\end{tabular}


Table 3. Literature reported $\left\{\mathrm{Mn}_{2}^{\mathrm{III}}{ }_{2} \mathrm{Mn}_{2}{ }_{2}\right\}$ butterfly complexes with their formula, magnetic exchange interactions $(J)$, ground spin state $S_{g s}$ value and uniaxial magnetic anisotropy parameter $D$ of the ground spin state.

\begin{tabular}{|c|c|c|c|c|c|}
\hline Molecular Formula & $\begin{array}{l}J_{\mathrm{bb}} \\
\left(\mathrm{cm}^{-1}\right)\end{array}$ & $\begin{array}{l}J_{\mathrm{wb}} \\
\left(\mathrm{cm}^{-1}\right)\end{array}$ & $S_{\mathrm{gs}}$ & $\begin{array}{l}D \\
\left(\mathrm{~cm}^{-1}\right)\end{array}$ & Ref \\
\hline$\left[\mathrm{Mn}_{4} \mathrm{O}_{2}(2 \text {-Cl-benzoato })_{7}(\text { bpy })_{2}\right]$ & -23.2 & -4.9 & $7 / 2$ & -0.6 & {$[1 \mathrm{~b}]$} \\
\hline$\left[\mathrm{Mn}_{4} \mathrm{O}_{2}(2 \text {-Br-benzoato })_{7}(\text { bpy })_{2}\right]$ & -22.8 & -4.7 & $7 / 2$ & & {$[1 \mathrm{~b}]$} \\
\hline$\left[\mathrm{Mn}_{4}(\mathrm{HX})_{4} \mathrm{Cl}_{2}(\mathrm{MeOH})_{4}\right] \cdot 2 \mathrm{Et}_{2} \mathrm{O}$ & 7.7 & 3.4 & 9 & & {$[1 \mathrm{c}]$} \\
\hline$\left[\mathrm{Mn}_{4}(\mathrm{HX})_{4} \mathrm{Br}_{2}(\mathrm{MeOH})_{4}\right] \cdot 2 \mathrm{Et}_{2} \mathrm{O}$ & 12.4 & 3.3 & 9 & & {$[1 \mathrm{c}]$} \\
\hline$\left[\mathrm{Mn}_{4}(\mathrm{hmp})_{6} \mathrm{Br}_{2}\left(\mathrm{H}_{2} \mathrm{O}\right)_{2}\right] \mathrm{Br}_{2} \cdot 4 \mathrm{H}_{2} \mathrm{O}$ & 12.7 & 1.3 & 9 & -0.35 & {$[1 \mathrm{~d}]$} \\
\hline$\left[\mathrm{Mn}_{4}(\mathrm{hmp})_{6}(\mathrm{MeCN})_{2}\left(\mathrm{H}_{2} \mathrm{O}\right)_{2}\right]\left(\mathrm{ClO}_{4}\right)_{4} \cdot 2 \mathrm{MeCN}$ & 5.9 & 0.46 & 9 & -0.23 & {$[1 \mathrm{e}]$} \\
\hline$\left[\mathrm{Mn}_{4}(\mathrm{hmp})_{6}\left(\mathrm{MeCO}_{2}\right)_{2}\left(\mathrm{H}_{2} \mathrm{O}\right)_{2}\right]\left(\mathrm{ClO}_{4}\right)_{2} \cdot 4 \mathrm{H}_{2} \mathrm{O}$ & 5.6 & 0.54 & 9 & -0.22 & {$[1 \mathrm{f}]$} \\
\hline$\left[\mathrm{Mn}_{4}(\mathrm{hmp})_{6}\left(\mathrm{PhCO}_{2}\right)_{2}\left(\mathrm{H}_{2} \mathrm{O}\right)_{2}\right]\left(\mathrm{ClO}_{4}\right)_{2} \cdot 4 \mathrm{MeCN} \cdot 2 \mathrm{H}_{2} \mathrm{O}$ & 5.2 & 0.9 & 9 & -0.26 & {$[1 \mathrm{f}]$} \\
\hline$\left[\mathrm{Mn}_{4}(\mathrm{hmp})_{6}\left(\mathrm{MeCO}_{2}\right)_{2}\right]\left(\mathrm{ClO}_{4}\right)_{2} \cdot \mathrm{H}_{2} \mathrm{O}$ & 4.5 & 1.3 & 9 & & {$[1 \mathrm{f}]$} \\
\hline$\left[\mathrm{Mn}_{4}(\mathrm{hmp})_{6}\left(\mathrm{ClCH}_{2} \mathrm{CO}_{2}\right)_{2}\right]\left(\mathrm{ClO}_{4}\right)_{2} \cdot 2 \mathrm{H}_{2} \mathrm{O}$ & 4.9 & 1.1 & 9 & & {$[1 \mathrm{f}]$} \\
\hline$\left[\mathrm{Mn}_{4}(\mathrm{hmp})_{6}\left(\mathrm{Cl}_{3} \mathrm{CCO}_{2}\right)_{2}\left(\mathrm{H}_{2} \mathrm{O}\right)_{2}\right]\left(\mathrm{ClO}_{4}\right)_{2}$ & 3.7 & 0.6 & 9 & & {$[1 \mathrm{f}]$} \\
\hline$\left[\mathrm{Mn}_{4}(\mathrm{hmp})_{6}\left(\mathrm{NO}_{3}\right)_{2}(\mathrm{MeCN})_{2}\right]\left(\mathrm{ClO}_{4}\right)_{2} \cdot 2 \mathrm{MeCN}$ & 6.3 & 4.2 & 9 & -0.22 & {$[1 \mathrm{~g}]$} \\
\hline$\left[\mathrm{Mn}_{4}(\mathrm{hmp})_{6}\left(\mathrm{NO}_{3}\right)_{2}\left(\mathrm{NO}_{3}\right)_{2}\right] \cdot \mathrm{MeCN}$ & 9.9 & 1.0 & 9 & -0.19 & {$[1 \mathrm{~g}]$} \\
\hline$\left[\mathrm{Mn}_{4}(\mathrm{hmp})_{6}(\mathrm{acac})_{2}(\mathrm{MeOH})_{4}\right]\left(\mathrm{ClO}_{4}\right)_{2}$ & 5.3 & 0.77 & 9 & -0.22 & {$[1 \mathrm{~g}]$} \\
\hline$\left[\mathrm{Mn}_{4}(\mathrm{hmp})_{6}\left(\mathrm{H}_{2} \mathrm{O}\right)_{2}\left(\mathrm{NO}_{3}\right)_{2}\right]\left(\mathrm{ClO}_{4}\right)_{2} \cdot 4 \mathrm{H}_{2} \mathrm{O}$ & 9.2 & 0.85 & 9 & -0.24 & {$[1 \mathrm{k}]$} \\
\hline$\left[\mathrm{Mn}_{4}(\mathrm{hmp})_{6}\left(\mathrm{~N}_{3}\right)_{2}\right]\left(\mathrm{ClO}_{4}\right)_{2}$ & 6.0 & 0.5 & 9 & & {$[1 \mathrm{k}]$} \\
\hline$\left[\mathrm{Mn}_{4}(\mathrm{Hpdm})_{6}\left(\mathrm{MeCO}_{2}\right)_{2}\right]\left(\mathrm{ClO}_{4}\right)_{2} \cdot 2.5 \mathrm{H}_{2} \mathrm{O}$ & 8.7 & 1.1 & 9 & -0.26 & {$[11]$} \\
\hline$\left[\mathrm{Mn}_{4}(\mathrm{hmp})_{6}\left(\mathrm{NO}_{3}\right)_{2}(\mathrm{den})_{2}\right] \cdot 2 \mathrm{MeCN}$ & 6.8 & 1.12 & 9 & -0.24 & {$[1 \mathrm{~m}]$} \\
\hline$\left[\mathrm{Mn}_{4}(\mathrm{hmp})_{6}(\mathrm{dcn})_{2}\right]\left(\mathrm{ClO}_{4}\right)_{2}$ & 6.3 & 0.7 & 9 & & {$[1 \mathrm{~m}]$} \\
\hline$\left[\mathrm{Mnn}_{4}(\mathrm{hmp})_{4}(\mathrm{Hpdm})_{2}(\mathrm{dcn})_{2}\right]\left(\mathrm{ClO}_{4}\right)_{2} \cdot 2 \mathrm{H}_{2} \mathrm{O} \cdot 2 \mathrm{MeCN}$ & 8.8 & 0.8 & 9 & -0.28 & {$[1 \mathrm{~m}]$} \\
\hline$\left[\mathrm{Mn}_{4}(\mathrm{hmp})_{4} \mathrm{Br}_{2}(\mathrm{MeO})_{2}(\mathrm{dcn})_{2}\right] \cdot 0.5 \mathrm{H}_{2} \mathrm{O} \cdot 2$ thf & 7.6 & 0.9 & 9 & & {$[1 \mathrm{~m}]$} \\
\hline$\left[\mathrm{Mn}_{4}(\mathrm{Hpdm})_{6}\left(\mathrm{MeCO}_{2}\right)_{2}\right]\left(\mathrm{ClO}_{4}\right)_{2} \cdot 2 \mathrm{MeCN} \cdot 2 \mathrm{Et}_{2} \mathrm{O}$ & 8.1 & 0.42 & 8 & -0.24 & {$[1 \mathrm{n}]$} \\
\hline$\left[\mathrm{Mn}_{4}\left(\mathrm{teaH}_{2}\right)_{2}(\mathrm{teaH})_{2}\left(\mathrm{PhCO}_{2}\right)_{2}\right]\left(\mathrm{PhCO}_{2}\right)_{2} \cdot \mathrm{MeCN}$ & 6.6 & 0.42 & 9 & & {$[1 \mathrm{o}]$} \\
\hline$\left[\mathrm{Mn}_{4}\left(\mathrm{teaH}_{2}\right)_{2}(\text { teaH })_{2}\left(\mathrm{MeCO}_{2}\right)_{2}\right]\left(\mathrm{MeCO}_{2}\right)_{2} \cdot 2 \mathrm{H}_{2} \mathrm{O}$ & 6.5 & 1.7 & 9 & & [10] \\
\hline$\left[\mathrm{Mn}_{4}\left(\text { teaH }_{2}\right)_{2}(\text { teaH })_{2}\left(\mathrm{EtCO}_{2}\right)_{2}\right]\left(\mathrm{ClO}_{4}\right)_{2}$ & 10.9 & 0.2 & 9 & & {$[10]$} \\
\hline$\left[\left\{\mathrm{Mn}_{4}(\mathrm{hmp})_{6}(\mathrm{MeCN})_{2}\right\}\left\{\mathrm{Pt}(\mathrm{mnt})_{2}\right\}_{4}\right]\left[\mathrm{Pt}(\mathrm{mnt})_{2}\right]_{2}$ & 10.0 & 0.56 & 9 & -0.21 & {$[1 \mathrm{q}]$} \\
\hline$\left[\left\{\mathrm{Mn}_{4}(\mathrm{hmp})_{6}(\mathrm{MeCN})_{2}\right\}\left\{\mathrm{Pt}(\mathrm{mnt})_{2}\right\}_{2}\right]\left[\mathrm{Pt}(\mathrm{mnt})_{2}\right]_{2} \cdot 2 \mathrm{MeCN}$ & 4.3 & 0.6 & 9 & -0.17 & [1q] \\
\hline$\left[\mathrm{Mn}_{4}(\mathrm{hmp})_{4}(\mathrm{OH})_{2} \mathrm{Mn}(\mathrm{den})_{6}\right] \cdot 2 \mathrm{MeOH} \cdot 2 \mathrm{thf}$ & 4.9 & 1.0 & 9 & -0.28 & {$[1 \mathrm{r}]$} \\
\hline$\left[\mathrm{Mn}_{4}(\mathrm{hmp})_{6}\left(\mathrm{NO}_{3}\right)_{2}\left(\mathrm{H}_{2} \mathrm{O}\right)_{2}\right]\left(\mathrm{NO}_{3}\right)_{2} \cdot 2.5 \mathrm{H}_{2} \mathrm{O}$ & 4.9 & 0.6 & 9 & -0.24 & {$[1 \mathrm{~s}]$} \\
\hline$\left[\mathrm{Mn}_{4}(\mathrm{hmp})_{6}\left(\mathrm{H}_{2} \mathrm{O}\right)_{4}\right]\left(\mathrm{ClO}_{4}\right)_{4} \cdot 2 \mathrm{H}_{2} \mathrm{O}$ & 3.5 & 0.39 & 9 & & {$[1 \mathrm{~s}]$} \\
\hline$\left[\mathrm{Mn}_{4}(\mathrm{hmp})_{6}(\mathrm{Hhmp})_{2}\right]\left(\mathrm{ClO}_{4}\right)_{4} \cdot 2 \mathrm{MeCN}$ & 0.17 & -0.64 & 1 & & {$[1 \mathrm{~s}]$} \\
\hline$\left[\mathrm{Mn}_{4}(\mathrm{bdea})_{2}(\mathrm{bdeaH})_{2}\left({ }^{t} \mathrm{BuCO}_{2}\right)_{4}\right]$ & 4.7 & 0.3 & 9 & -0.19 & {$[1 \mathrm{u}]$} \\
\hline$\left[\mathrm{Mn}_{4}(\mathrm{bdea})_{2}(\mathrm{bdeaH})_{2}\left(\mathrm{PhCO}_{2}\right)_{4}\right]$ & 7.7 & 0.9 & 9 & -0.24 & {$[1 \mathrm{u}]$} \\
\hline $\begin{array}{l}{\left[\mathrm{Mn}_{4}\left(\text { teaH }_{2}\right)_{2}(\text { teaH })_{2}\left(\mathrm{PhCO}_{2}\right)_{2}\right]\left(\mathrm{PhCO}_{2}\right)_{2} \cdot 0.7 \mathrm{MeCN} \cdot 0.3} \\
\text { EtOH }\end{array}$ & 8.5 & 1.8 & 9 & -0.23 & {$[1 \mathrm{u}]$} \\
\hline
\end{tabular}

The fits obtained for the $\chi_{M} T$ plots using PHI and Eq. 2, for Class 1 complexes, $\mathbf{1}-\mathbf{8}$, labeled Fit-x ?? in Figure 3 are generally very good over the $2-300 \mathrm{~K}$ range. The $J$ values for the $S_{\mathrm{gs}}=9$ ground state systems typically have both $J_{\mathrm{wb}}$ and $J_{\mathrm{bb}}$ positive with $J_{\mathrm{wb}}<J_{\mathrm{bb}}$. The $J$ values for 3, 4, 5 and $\mathbf{6}$ being similar to those reported elsewhere for other hmp and triethanolamine analogues. ${ }^{\mathbf{1 j}, \mathbf{1 0}, \mathbf{2 b}, \mathbf{2 d}}$ The $J_{\mathrm{bb}}$ values for 1 and 2, however, are smaller than generally observed. Complexes 7 and $\mathbf{8}$, with smaller $\chi_{M} T$ (max) values, gave good fits for negative $J_{\mathrm{wb}}$ values and a $S_{\mathrm{gs}}=1$ ground state.

For Class $2(9-12)$ the best fit parameters for compound 9 revealed an $S_{\mathrm{gs}}=9$ ground state which is different to that previously published, viz. $J_{w b}\left(\mathrm{Mn}^{\mathrm{II}} \cdots \mathrm{Mn}^{\mathrm{III}}\right)=5.8 \mathrm{~cm}^{-1}$ and $J_{b b}\left(\mathrm{Mn}^{\mathrm{II}} \cdots \mathrm{Mn}^{\mathrm{II}}\right)=-8.7 \mathrm{~cm}^{-1}$ for $g=2 ; S_{\mathrm{gs}}=6 .{ }^{1 \mathrm{~h}}$ In a similar vein the best fit parameters for complex $\mathbf{1 1}$ are different to those previously published. The parameters are of the same sign, but different in magnitude, viz. $J_{\mathrm{wb}}=1.41 \mathrm{~cm}^{-1}, J_{\mathrm{bb}}=$ $1.38 \mathrm{~cm}^{-1}, g\left(\mathrm{Mn}^{\mathrm{III}}\right)=1.93$ and $g\left(\mathrm{Mn}^{\mathrm{II}}\right)=2.00 ; S_{\mathrm{gs}}=8$ with $\mathrm{S}_{\mathrm{gs}}=7$ excited states close in energy to the ground state. ${ }^{1 \mathrm{~m}}$ The different parameters for both $\mathbf{9}$ and $\mathbf{1 1}$ found in this study may be attributed to the fact that we have simultaneously fitted both the susceptibility and the magnetization data using Eq. 2 as well as the fit being insensitive to the $J_{\mathrm{bb}}$ values. As the later procedure is more reliable and with the extracted values being in agreement with DFT estimated parameters, this offers confidence on the parameters extracted. Complex 12 shows similar $J$ values to those published with a ground spin state of $S_{\mathrm{gs}}=1 .{ }^{1 \mathbf{j}}$ The best fit for the new complex 10 reverses the sign of $J_{\mathrm{wb}}$ and $J_{\mathrm{bb}}$ interactions compared to $\mathbf{1 2}$ resulting in a degenerate ground state situation with the lowest lying spin values ranging from $S_{\mathrm{gs}}=1$ -4 .

Magnetization isotherms in the temperature range 2 - $20 \mathrm{~K}$ were measured in order to back up the identification of the ground state and provide information on low lying excited states, anisotropy, etc. Perusal of Figures 4 and SF $19-21$ show that fits using Eq. 2 for 1 
and 5, and 2, 3, 4, 6 and $\mathbf{9}-\mathbf{1 1}$ (ESI) are very good for the isotherms with $M$ values in a dc field 0.5 to $3.5 \mathrm{~T}$. The fits are excellent in the low temperature region due to the inclusion of the zero field splitting in the exchange model (See Table 2). Isothermal $M$ vs $H$ fits for the $S_{\mathrm{gs}}=1$ Class 1 complexes $(\mathbf{7}$ and $\mathbf{8})$ and the $S_{\mathrm{gs}}=1$ Class 2 complex (12) are generally satisfactory, with the zero field splitting parameter being less important, with the fits yielding negligible values (See Table 2).

The extracted $D$ values using Eq. 2 for the $S_{\mathrm{gs}}=9$ complexes are in the range of -0.32 to $-0.43 \mathrm{~cm}^{-1}$ which are similar to the literature reported $D$ values of other manganese butterfly complexes ${ }^{5}$ (See Table 2) offering confidence on the parameters extracted.
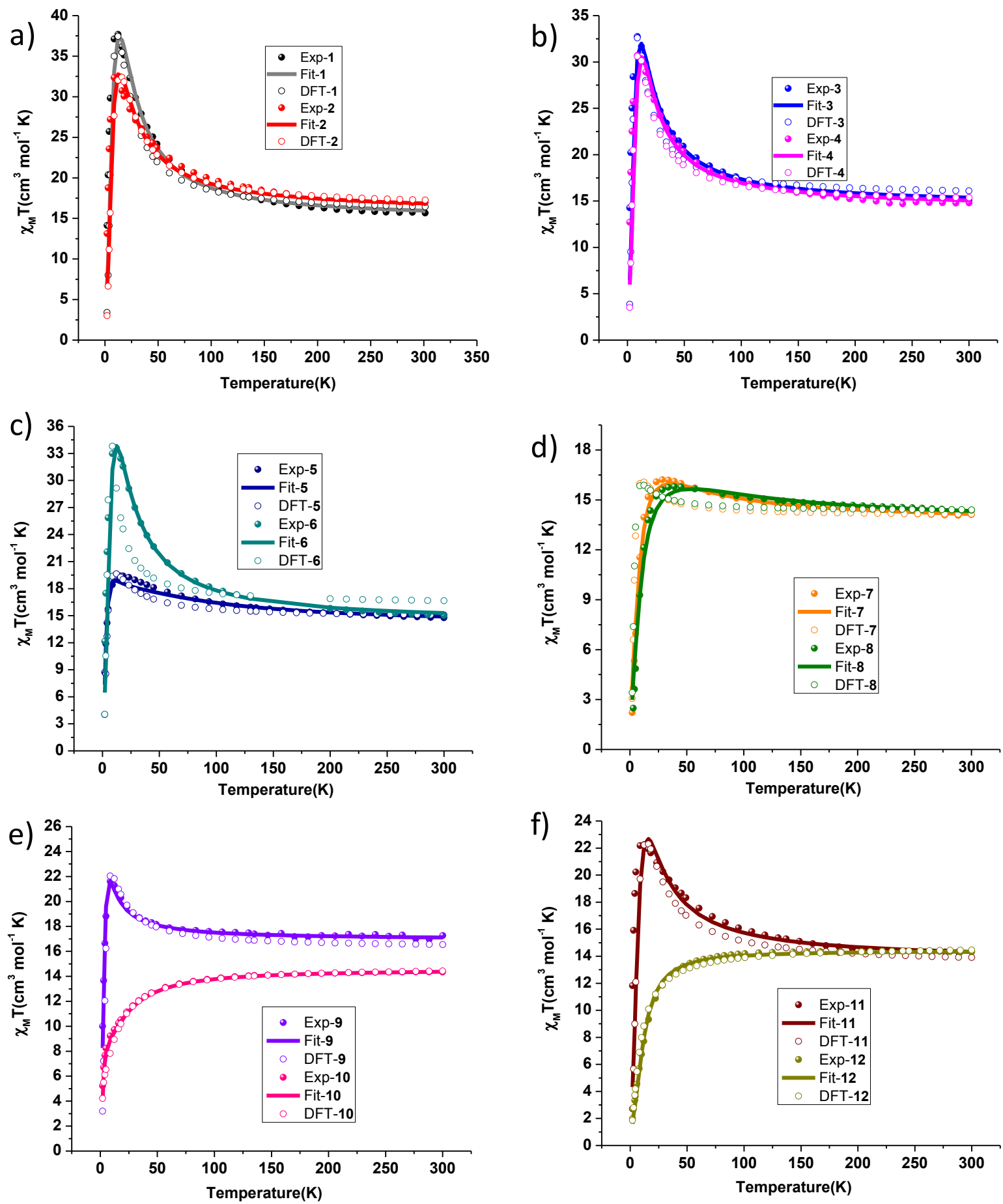

Figure 3. Thermal variation of $\chi_{M} T$ for a) 1 - 2; b) 3 - 4; c) 5 -6; d) 7 - 8; e) 9 - 10 and f) 11 - 12 down to 2 K, at $1 \mathrm{~T}$. The solid lines are fits 
of the experimental data using the PHI program. The open points are the simulated $\chi_{\mathrm{M}} T(\mathrm{~T})$ values using DFT extracted parameters.
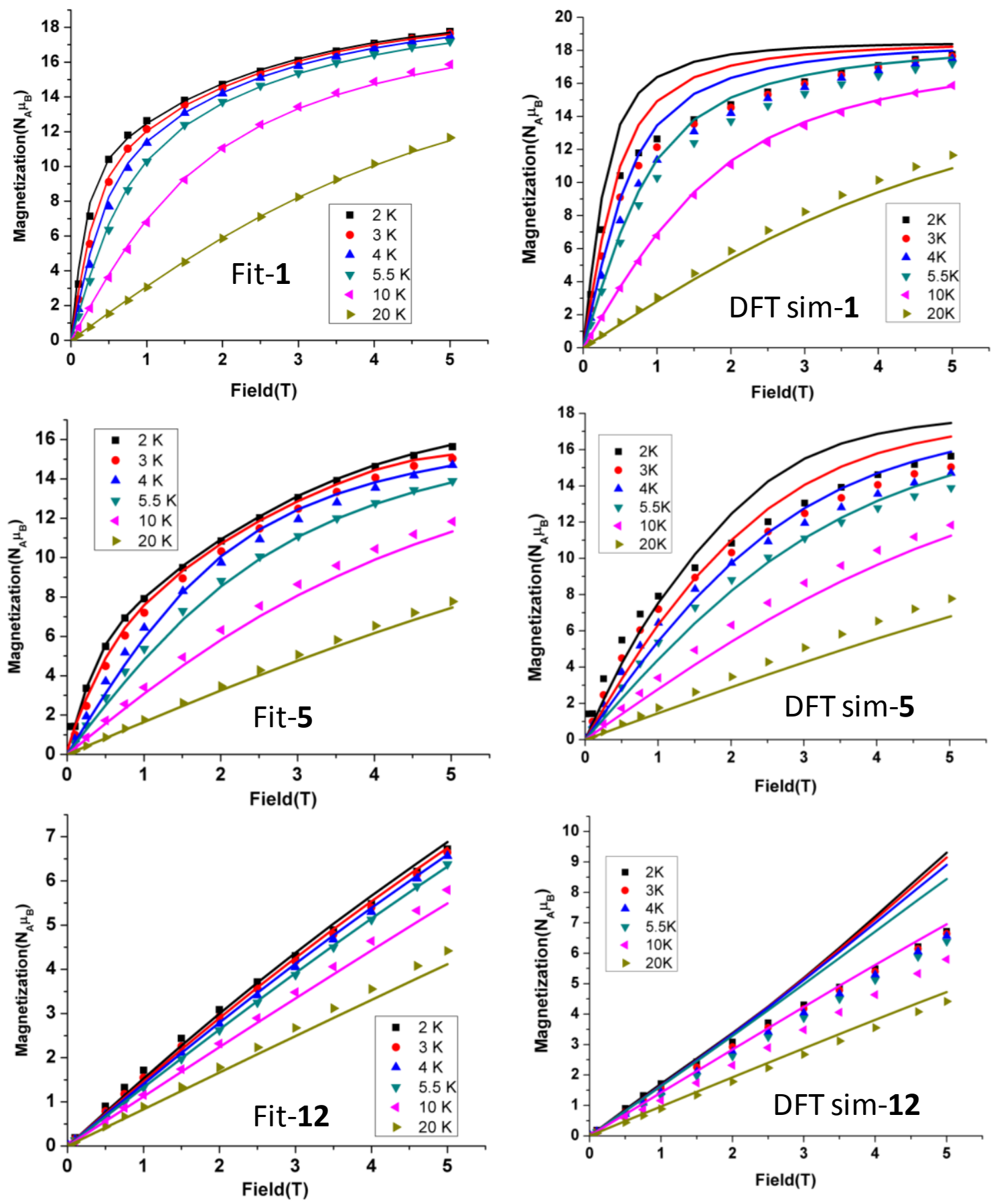

Figure 4. $M$ vs $H$ isotherms for (top) 1, (centre) 5 and (bottom) 12 at temperatures 2, 3, 4, 5.5, 10 and $20 \mathrm{~K}$. The color shapes are experimental 
data, the color lines are fits of the experimental data (left), and simulation with the DFT computed $J$ parameters (right).

\section{AC susceptibility studies}

Alternating current (ac) susceptibility measurements were performed to determine if $\mathbf{1} \mathbf{- 1 2}$ display slow magnetization reversal. It was found that slow magnetization relaxation is indeed observed for all complexes, except for $\mathbf{1 0}$ and $\mathbf{1 2}$, as determined from the appearance of frequency and temperature dependent out-of-phase susceptibility $\left(\chi_{M}\right.$ ") signals. The $\chi_{M}$ " vs. $T$ plots of compounds $\mathbf{2}$ and $\mathbf{6}$ are shown in Figure 5 as representative examples, with plots of the remaining complexes shown in Figures SF8 - SF14, along with the in-phase $\chi_{M}{ }^{\prime}$ vs. $T$ and $\chi_{M}{ }^{\prime}$ vs. frequency plots. The relaxation times $(\tau)$ for $\mathbf{1}, \mathbf{2}, \mathbf{3}$, 6 and 9 are temperature dependent, and when plotted as $\ln (\tau)$ versus $1 / T$ display a linear relationship. Fitting the data to the Arrhenius law $\left[\tau=\tau_{o} \exp \left(U_{\text {eff }} / k_{B} T\right)\right]$ yielded anisotropy barriers $\left(U_{\text {eff }}\right)$ and pre-exponential factors $\left(\tau_{0}\right)$ of $\left\{13.1 \mathrm{~cm}^{-1}\right.$ and $\left.1.5 \times 10^{-8} \mathrm{~s}\right\}(\mathbf{1}),\left\{11.7 \mathrm{~cm}^{-1}\right.$ and $\left.3.6 \times 10^{-8} \mathrm{~s}\right\}(2),\left\{16.6 \mathrm{~cm}^{-1}\right.$ and $\left.2.6 \times 10^{-10} \mathrm{~s}\right\}(3),\left\{16.8 \mathrm{~cm}^{-1}\right.$ and 1.6 $\left.\mathrm{x} 10^{-8} \mathrm{~s}\right\}(6)$ and $\left\{11.8 \mathrm{~cm}^{-1}\right.$ and $\left.3.9 \times 10^{-8} \mathrm{~s}\right\}$ (9) (see Figure SF15). For complexes 5, 7, 8 and $\mathbf{1 1}$ no maxima are observed above $1.8 \mathrm{~K}$ suggesting smaller anisotropy barriers and faster relaxation times. For $\mathbf{7}$ and $\mathbf{8}$, while slow magnetization relaxation behavior is observed, the ground state $S$ value could not be uniquely determined (reported as $S=1$, in Table 2) as saturation in the magnetization is not observed. This indicates there are several close lying excited states as has been witnessed in several Mn clusters. ${ }^{13 \mathrm{~h}}$ Indeed, from the dc susceptibility fitting analysis it is found that excited states of value $S=0-6$ and $S=0-5$ remain populated even at $2 \mathrm{~K}$ for 7 and $\mathbf{8}$, respectively. This would lead to the conclusion that the slow relaxation originates from populated excited state(s), which is backed up by the small $\chi_{M}{ }^{\prime \prime} / \chi_{M}$ ' ratio of 0.03 . The absence of slow magnetic relaxation for $\mathbf{1 0}$ and $\mathbf{1 2}$ is due to the isolated $S=1$ ground state for $\mathbf{1 2}$ and the small spin and anisotropy found for $\mathbf{1 0 .}$
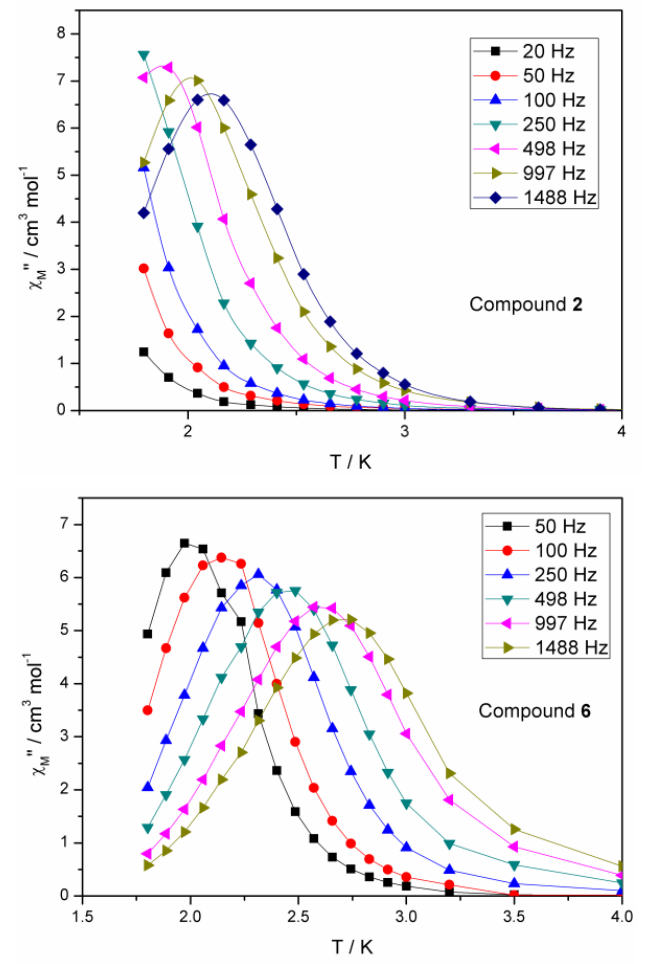

Figure 5. Temperature dependence of $\chi_{M}$ " for 2 (top) and 6 (bottom), with $H_{a c}=3.5 \mathrm{Oe}$ and $H_{d c}=0 \mathrm{Oe}$.
To understand the origin of the contrasting magnetic properties for these structurally related $\left\{\mathrm{Mn}^{\mathrm{II}}{ }_{2} \mathrm{Mn}^{\mathrm{III}}{ }_{2}\right\}$ butterfly complexes, we have undertaken a detailed DFT study performing calculations using B3LYP/TZV setup to estimate the exchange interactions and the zero-field splitting parameters.

\section{Theoretical Studies:}

Magnetic exchange coupling parameter $(\boldsymbol{J})$ Three exchange coupling constants are determined by DFT, and are calculated using the B3LYP hybrid functional. The exchange topology used to calculate and simulate the $J$ values is shown in Figure 2. We have set three goals that the DFT calculations can help elucidate. 1) to study the magnetic properties of the $\left\{\mathrm{Mn}_{2}{ }_{2} \mathrm{Mn}^{\mathrm{III}} 2\right\}$ butterfly complexes by calculating the exchange coupling constants $(J) ; 2)$ to develop magnetostructural correlations that will help us understand which structural parameters affect the $J$ values and 3) to calculate the zero field splitting $(\mathrm{ZFS})$ parameter $(D)$ to assess the nature of $D$ in determining the slow magnetization relaxation behavior of these complexes.

To gain confidence in the computed $J$ values, cross comparison of the DFT $J$ parameters with the fitted $J$ values obtained from the experimental magnetic data will be discussed, followed by the computed susceptibility data. This will then be followed by an analysis of geometrical correlation to the observed $J$ values.

The experimentally fitted and DFT computed $J$ values for complexes 1-12 are given in Table 2. It is found that, in general, the sign of the magnetic exchange can be reproduced between the two techniques. In many cases, however, the magnitude of the various exchange parameters differ, the results of which are summarized below.

As stated above the $J_{b b}$ parameter is fixed to the DFT calculated value. Thus, only $J_{w b}$ is variable in the experimental data fit. For complexes 1 - 4 (Class 1) it is found that the nature of the exchange interaction as determined from both the experimentally fitted parameters and the DFT calculated values are in agreement. The analysis reveals ferromagnetic magnetic exchange coupling for both $J_{w b}$ and $J_{b b}$ interactions, except for $\mathbf{2}$, where DFT predicts an antiferromagnetic interaction for $J_{\mathrm{bb}}$ (Table 2). The magnitude of the ferromagnetic $J_{w b}$ exchange is found to be slightly larger for the experimentally determined parameters compared to DFT. It was also determined from DFT that the $J_{w w}$ interaction is very weak and antiferromagnetic in all cases and can thus be ignored for fitting the magnetic data.

For 5 - 8 (Class 1), the parameters derived from the experimental data and DFT yield the same sign of $J_{w b}$ for $\mathbf{5}$ and $\mathbf{6}$, but differ for $\mathbf{7}$ and 8 (Table 2). The experimentally determined $J_{w b}$ parameters is ferromagnetic for $\mathbf{5}$ and $\mathbf{6}$ and antiferromagnetic for $\mathbf{7}$ and $\mathbf{8}$. The DFT calculations predict a ferromagnetic $J_{w b}$ interaction for $\mathbf{5}-\mathbf{8}$. In all cases the $J_{b b}$ interaction is ferromagnetic. As with $\mathbf{1}-\mathbf{4}$, DFT predicts that the $J_{\mathrm{ww}}$ interaction is negligible and antiferromagnetic.

For 9-12 (Class 2) the nature of the magnetic interaction is again in good agreement between the fitted and DFT parameters. The $J_{w b}$ interaction is found to be ferromagnetic, while $J_{b b}$ is antiferromagnetic for $9-\mathbf{1 1}$. This trend is reversed for $\mathbf{1 2}$.

A small error observed with the DFT calculated $J$ values are in the range of $0.002-0.008 \mathrm{~cm}^{-1}$.

The temperature dependence of $\chi_{M} T$ for the DFT calculated $J$ values provide satisfactory fits to the experimental data for $\mathbf{1}$ - $\mathbf{4}$ (see Figure $3 \mathrm{a}, 3 \mathrm{~b}$ and Figure SF16), 5 - 8 (see Figure 3c, 3d and Figure SF17) and 9-12. (See Figure 3e, 3f and Figure SF18). The DFT calculated magnetization data also afforded reasonable fits to the experimental 
$M v s H$ data for the majority of complexes, but with poor agreement at 2, 3 and $4 \mathrm{~K}$ and at intermediate field values. The fits using PHI and Eqn. 2 are superior (see Figure 4 top (1), center (5) and bottom (12) and Figure SF19-SF21 for 2-4 and 6-11). ${ }^{\mathbf{1 j}}$ At lower temperatures, the anisotropic contributions are likely to play a role and this has not been included in the DFT magnetization simulation.

Analysis of $J_{b b}$ for 1 - 12: This interaction, for all complexes, mediates through two alkoxo bridges and occurs between two $\mathrm{Mn}^{\mathrm{III}}$ centers in $\mathbf{1}-\mathbf{8}$ and two $\mathrm{Mn}^{\mathrm{II}}$ centers in 9 - 12. The interaction is found to be ferromagnetic from the DFT calculations (with the exception of 2) for Class 1 complexes, while it is antiferromagnetic in Class 2 (with the exception of 12). The magnitude of the DFT calculated $J_{\mathrm{bb}}$ parameter in Class 1 varies from +2.32 to $-0.06 \mathrm{~cm}^{-1}$. Table 1 lists all the geometrical parameters associated with $\mathbf{1}-\mathbf{1 2}$ and these are used to determine the reason behind the variation in the $J$ values. From previous work and by developing magneto-structural correlations on various $\mathrm{Mn}^{\mathrm{III}}(\mathrm{OR})_{2} \mathrm{Mn}^{\mathrm{III}}$ dimers, ${ }^{22}$ it was concluded that the orientation of the Jahn-Teller axes plays a pivotal role in determining the sign and strength of the $J$ parameter. For $\mathbf{1}-\mathbf{8}$ the interaction falls in the type II class, type II being defined in the dimer study mentioned above, ${ }^{22}$ and as expected the $J$ values are found to be weakly ferromagnetic or antiferromagnetic. ${ }^{22}$ This is essentially due to smaller overlap between the magnetic orbitals due to the parallel orientation of the Jahn-Teller axes (see Figure 6a for schematic illustration of interaction expected for this building unit). The computed $J$ values are found to be correlated to the $\mathrm{Mn}^{\mathrm{III}}-\mathrm{Mn}^{\mathrm{III}}$ distance, with shorter distances yielding ferromagnetic coupling and longer distances yielding weaker ferromagnetic or even antiferromagnetic interactions. This trend is clearly visible from Table 1 , with shorter $\mathrm{Mn}^{\mathrm{III}}-\mathrm{Mn}^{\mathrm{III}}$ distances revealing ferromagnetic interactions. However, the variation in the $\mathrm{Mn}^{\mathrm{III}}-\mathrm{Mn}^{\mathrm{III}}$ distances are also correlated to the variation in the $\mathrm{Mn}^{\mathrm{III}}-\mathrm{O}$ distance and $\mathrm{Mn}^{\mathrm{III}}-\mathrm{O}-\mathrm{Mn}^{\mathrm{III}}$ angles. Correlations developed earlier suggest that these are the two key parameters influencing the magnitude of $J$ in type II dimers. ${ }^{22}$

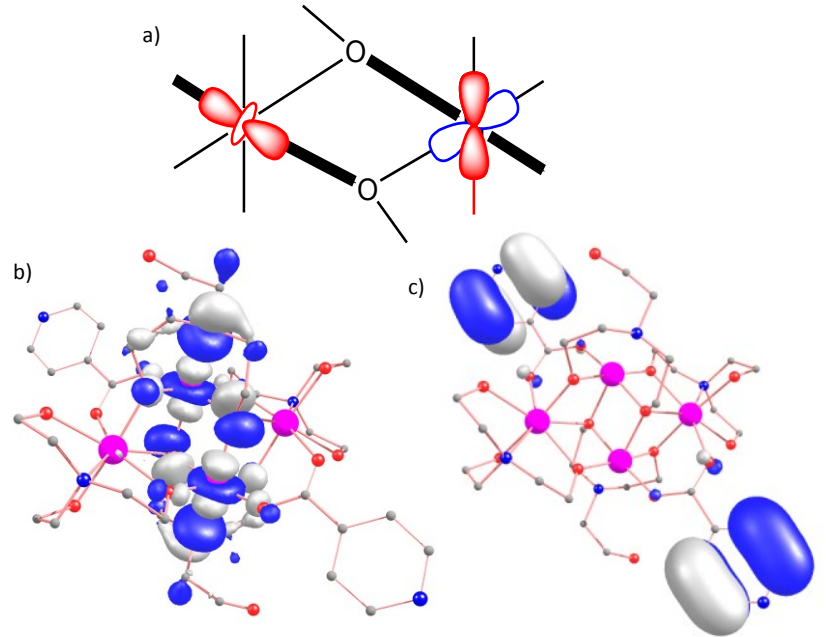

Figure 6. a) Schematic illustration of the interaction in type II complexes. ${ }^{22}$ The bold lines along the $\mu-\mathrm{O}$ bonds represent the JT axes that visualises the parallel orientation. b) Singly Occupied Molecular Orbital (SOMO) of $\alpha$ - electron in 3. c) SOMO of $\beta$ - electron in 3. The white and blue colors represent positive and negative sign.

For complexes 9 - 12, the $\mathrm{Mn}^{\mathrm{II}}-\mathrm{Mn}^{\mathrm{II}}$ distance are also found to correlate to the magnitude of the $J$ value, as the distance increases the $J$ value is also found to increase, becoming less antiferromagnetic and in the case of 12, which has the largest $\mathrm{Mn}^{\mathrm{II}}-\mathrm{Mn}^{\mathrm{II}}$ distance the interaction is weakly ferromagnetic. Besides the $\mathrm{Mn}^{\mathrm{II}}-\mathrm{Mn}^{\mathrm{II}}$ distance there is also a correlation with the $\mathrm{Mn}^{\mathrm{II}}-\mathrm{O}-\mathrm{Mn}^{\mathrm{II}}$ angle, ${ }^{13 \mathrm{~h}}$ with an increasing angle resulting in a decrease in the magnitude of antiferromagnetic contribution to the net $J$ value.

Analysis of $J_{w b}$ for complexes 1-12: This interaction describes the magnetic exchange between a $\mathrm{Mn}^{\mathrm{III}}$ and a $\mathrm{Mn}^{\mathrm{II}}$ ion and is mediated by two alkoxo bridges for all complexes. The magnitude of $J$ from the DFT calculations is found to vary from +1.37 to $-0.45 \mathrm{~cm}^{-1}$. Analysis of the orbital interaction revealed that the $\mathrm{Mn}(\mathrm{III})-\mathrm{d}_{\mathrm{z}}{ }^{2} \mid \mathrm{Mn}(\mathrm{II})-\mathrm{d}_{\mathrm{z}}{ }^{2}$ overlap controls the sign and magnitude of the $J$ parameter. For all complexes, except for $\mathbf{1 2}$, the $\mathrm{d}_{\mathrm{z}}{ }^{2}-\mathrm{d}_{\mathrm{z}}{ }^{2}$ orbitals are parallel thus avoiding significant orbital overlap, leading to the absence of a significant antiferromagnetic contribution to the $J$ parameter. For complex 12, on the other hand, due to the variation of structure and the orientation of the Jahn-Teller axes, head-to-head $\mathrm{Mn}(\mathrm{III})-\mathrm{d}_{\mathrm{z}}{ }^{2} \mid \mathrm{Mn}(\mathrm{II})-\mathrm{d}_{\mathrm{z}}{ }^{2}$ overlap is detected leading to antiferromagnetic coupling (see Figure SF22 in ESI). The variation in the magnitude of the ferromagnetic $J$ 's are found to correlate to the $\mathrm{Mn}-\mathrm{O}-\mathrm{Mn}$ angles and the $\mathrm{Mn}-\mathrm{O}$ distances.

\section{Spin ground state and spin density analysis of 1 - 12}

The experimentally fitted and DFT computed $J$ values yield an $S=9$ ground state (see Figure 7a) for complexes $\mathbf{1}$ - 6, 9 and $\mathbf{1 1}$ (see Table 2 ). The ground state spin density plot for $S=9$ (DFT calculated) is shown in Figure 8a. In all complexes, spin delocalization is observed for the $\mathrm{Mn}(\mathrm{II})$ ions (spin density of $\sim 4.82$ ), whereas the $\mathrm{Mn}$ (III) ions display a mixture of spin delocalization and polarization $(\sim 3.86)$. From the delocalization, a significant spin density of (0.05) is found on the central $\mu_{3}-\mathrm{O}$ atoms that bridge the two body ions to the wing ions, while the outer $\mu_{2}-\mathrm{O}$ atoms bridging a body to a wing site gain a spin density of (0.03).
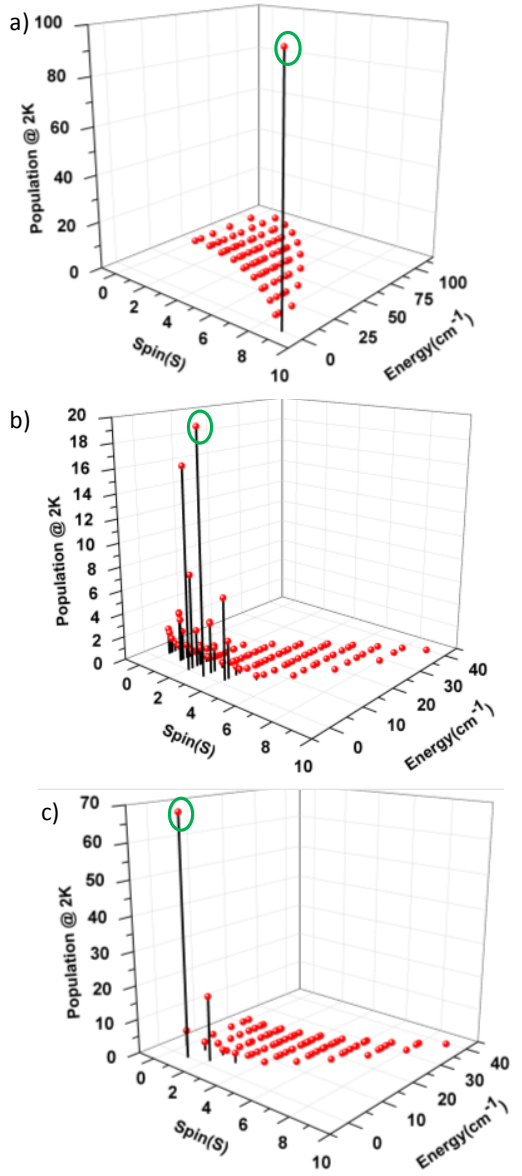
Figure 7. Eigen value plots for (a) $\mathbf{1}$ (a similar diagram is applicable for complexes $\mathbf{2}$ - 9 and 11); (b) 10 and (c) 12 (the spin ground state is highlighted).

For complexes $\mathbf{7}$ and $\mathbf{8}$, DFT computed $J$ values suggest an $S=9$ ground state, however the same value could not be unambiguously determined from the experimental data. As the exchange interactions are very weak for these complexes, this leads to several nested spin states (nearly ten spin states lie within an energy window of $5 \mathrm{~cm}^{-1}$ ). For complex 10, the experimental $J$ values predict that spin states of $S=1-4$ are lowest in energy, while the DFT computed $J$ values yield an $S=3$ ground state (see Figure $7 \mathrm{~b})$. The spin state $(S=4)$ near to the ground state for complex 10 (DFT) is achieved when one body $\mathrm{Mn}(\mathrm{II})$ ion has a "spin-down" configuration, while the other Mn centers are "spin-up". This is realized as the dominant interaction predicted in $\mathbf{1 0}$ is $J_{\mathrm{bb}}$, which is antiferromagnetic $\left(-0.88 \mathrm{~cm}^{-1}\right)$, whereas the $J_{\mathrm{wb}}$ interactions is weaker and computed to be ferromagnetic $\left(0.32 \mathrm{~cm}^{-1}\right)$. This spin configuration should lead to an overall $S=4$ value for the ground state. However due to the competing nature of the interactions, the calculation revealed an $S=3$ ground state. The spin density plot for $S=4$ is shown in Figure $8 \mathrm{~b}$ and the mechanism of delocalization is similar to that discussed above.

a)
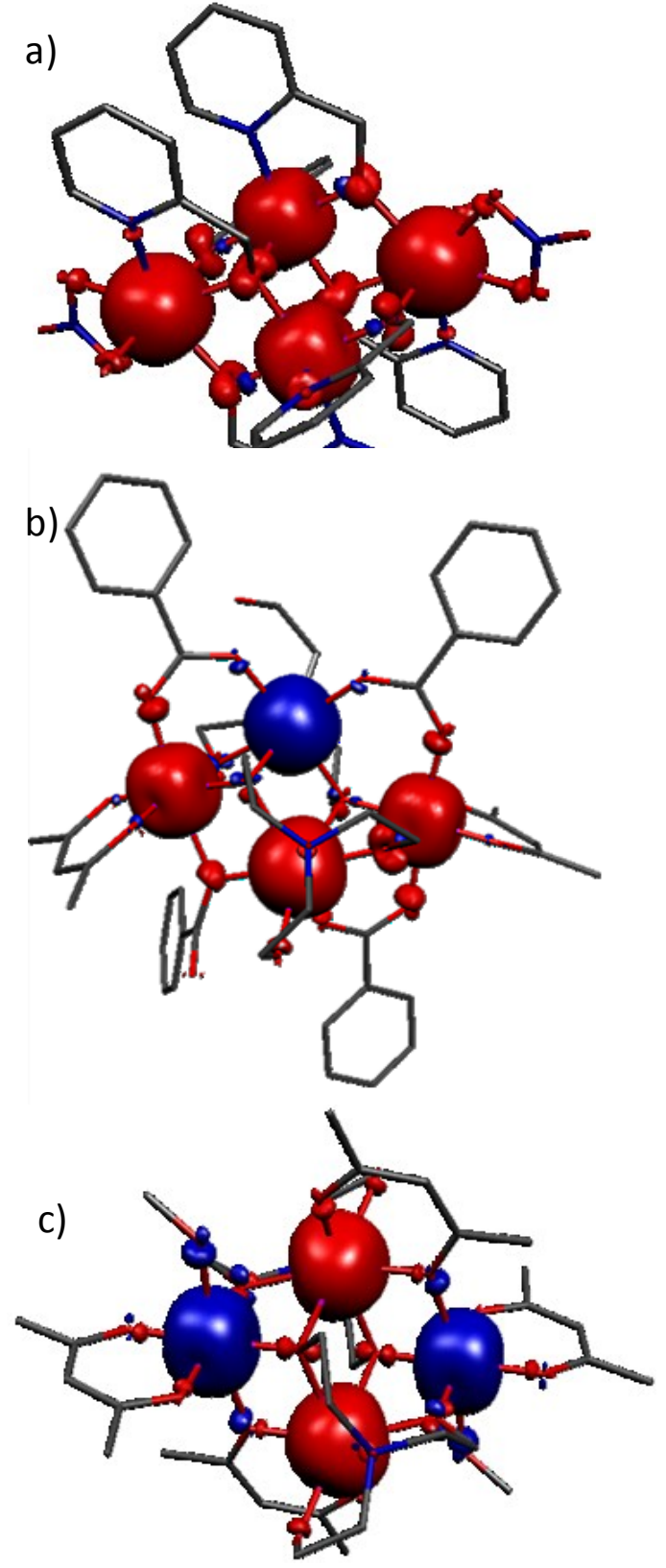

Figure 8. Spin density plots of complex a) 1; b) 10 and c) 12. The red and blue colors represent positive and negative spin densities.

For complex 12 the experimental fit and the computed $J$ values yield an $S=1$ ground state (see Figure 7c). The spin ground state is attained when two wing Mn(III) ions are "spin-down", while the body $\mathrm{Mn}$ (II) ions are "spin-up". The dominant interaction predicted in complex 12 is the antiferromagnetic $J_{\mathrm{wb}}\left(-0.45 \mathrm{~cm}^{-1}\right)$ pathway. Even though $J_{\mathrm{bb}}$ and $J_{\mathrm{ww}}$ are ferromagnetic, they are negligible in magnitude $\left(0.02\right.$ and $\left.0.01 \mathrm{~cm}^{-1}\right)$ and do not play a role in determining the ground state. The ground state spin density plot for $S=1$ is shown in Figure $8 \mathrm{c}$. Here the spin-down $\mathrm{Mn}(\mathrm{III})$ ions have a spin density of $\sim$ -3.84 . The central bridging $\mu_{3}-\mathrm{O}$ atoms and $\mu_{2}-\mathrm{O}$ display a spin density of (0.01) and (-0.01), respectively.

\section{Magnetic Anisotropy:}

Table 4. B3LYP-computed $D, E / D, g$ values along with the different contributions to the computed ZFS parameter for $\mathbf{1 - 9}$ and $\mathbf{1 2}$.

\begin{tabular}{|c|c|c|c|c|c|}
\hline \multirow[b]{2}{*}{ Complex } & \multicolumn{5}{|c|}{ DFT Calculated values } \\
\hline & $D\left(\mathrm{~cm}^{-1}\right)$ & $E / D$ & $\begin{array}{c}D_{\mathrm{SOC}} \\
\left(\mathrm{cm}^{-1}\right)\end{array}$ & $\begin{array}{c}D_{\mathrm{SS}} \\
\left(\mathrm{cm}^{-1}\right)\end{array}$ & $\begin{array}{l}g \text { (iso- } \\
\text { tropic) }\end{array}$ \\
\hline 1 & -0.062 & 0.219 & -0.033 & -0.029 & 2.002 \\
\hline 2 & -0.152 & 0.311 & -0.122 & -0.030 & 2.001 \\
\hline 3 & -0.19 & 0.079 & -0.159 & -0.031 & 2.001 \\
\hline 4 & -0.183 & 0.293 & -0.166 & -0.017 & 2.002 \\
\hline 5 & -0.067 & 0.161 & -0.035 & -0.032 & 2.002 \\
\hline 6 & -0.191 & 0.064 & -0.161 & -0.03 & 2.001 \\
\hline 7 & -0.051 & 0.201 & -0.031 & -0.02 & 2.002 \\
\hline 8 & -0.065 & 0.149 & -0.034 & -0.031 & 2.002 \\
\hline 9 & -0.073 & 0.113 & -0.037 & -0.036 & 2.001 \\
\hline 11 & -0.069 & 0.211 & -0.038 & -0.031 & 2.002 \\
\hline
\end{tabular}

Following on from the determination of the magnetic exchange parameters and spin values, we then proceeded to calculate the cluster $g$ and $D$ parameters, using DFT for the complexes possessing an $S=$ 9 ground state (1 - 9, and 11). Although ab initio CASSCF calculations have proven to give good numerical estimates of cluster $D$ values, this procedure cannot be employed to obtain ground state anisotropy for large clusters such as the ones studied here. ${ }^{19 c-e, 23}$ Thus the calculated $D$ values are underestimated compared to the extracted $D$ values from the experimental data. The computed isotropic $g$ values 
for $\mathbf{1} \mathbf{- 9}$, and $\mathbf{1 1}$ are given in Table 4, along with the ZFS parameters (D). The computed $g$ tensors are found to be isotropic for the $S=9$ ground state for $\mathbf{1}-\mathbf{9}$ and $\mathbf{1 1}$ and the calculations reveal a negative sign of $D$ for these complexes. The different contributions to the net $D$ parameter are also summarized in Table 4 . It is observed that $D_{\text {soc }}$ (spin-orbit) makes a significant contribution to the net ZFS parameter compared to the $D_{\mathrm{SS}}$ (spin-spin) contribution in the cases of largest $D$. This is found for $\mathbf{2 , 3 , 4}$ and $\mathbf{6}$. The other complexes reveal a smaller negative ZFS parameter, with equal contributions from $D_{\text {soc }}$ and $D_{S S}$. The different contribution of $D_{\text {soc }}$ is listed in Table ST4. The largest contribution to the $D_{\text {soc }}$ component for complexes 2, 3, 4 and $\mathbf{6}$ are found to arise from spin-flip excitations $\alpha(\mathrm{SOMO}$, Singly Occupied Molecular Orbital)---> $>$ (SOMO) excitations as well as a spinconserving excitations (SOMO---> VMO (virtual molecular orbital). Here the $\alpha--->\beta$ spin-flip excitations are more prominent and contribute in the range of $70-80 \%$ to the total $D$ value in $\mathbf{2 , 3 , 4}$ and $\mathbf{6}$. A closer look at the molecular orbitals reveal that this transition corresponds to metal ( $\mathrm{d}_{\mathrm{z} 2}$ orbitals of $\mathrm{Mn}^{\mathrm{III}}$, See Figure $6 \mathrm{~b}$ ) to ligand (low lying $\pi^{*}$ orbitals of the substituent attached to the bridging carboxylic acid, e.g. in complex 3 it corresponds to $\pi^{*}$ orbitals of isonicotinic acid, see Figure $6 \mathrm{c}$ ). The absence of such substituents leads to highenergy $\alpha($ SOMO)---> $\beta($ SOMO) excitations and therefore smaller contributions to the total $D$ parameter (for example in complex 5). This invariably suggests that the electron donating and withdrawing substituent's not only influence the magnitude of the $J$ values but also the magnetic anisotropy by offering lower energy excitations and hence enhanced $D_{\text {soc }}$ contributions.

\section{Magneto-Structural Correlations:}

We have developed magneto-structural correlations for complex 3 (Class 1) and Complex 9 (Class 2) to rationalize the structural parameters that affect the magnetic exchange interactions within these complexes. Correlations for five structural parameters which can affect the exchange interaction have been developed (see Figure 9): 1) $\mathrm{Mn}_{\mathrm{b}^{-}}$ $\mathrm{O}$ bond distance; 2) $\mathrm{Mn}_{\mathrm{w}}-\mathrm{O}$ bond distance; 3) $\mathrm{Mn}_{b}-\mathrm{O}-\mathrm{Mn}_{\mathrm{b}}$ angle $(\alpha)$; 4) $\mathrm{Mn}_{b}-\mathrm{O}-\mathrm{Mn}_{b}-\mathrm{O}$ dihedral angle( $\left.\mathrm{\gamma}\right)$ and 5) Out-of-plane shift of the $\operatorname{Mn}_{\mathrm{w}}$ atoms $(\beta){ }^{24}$

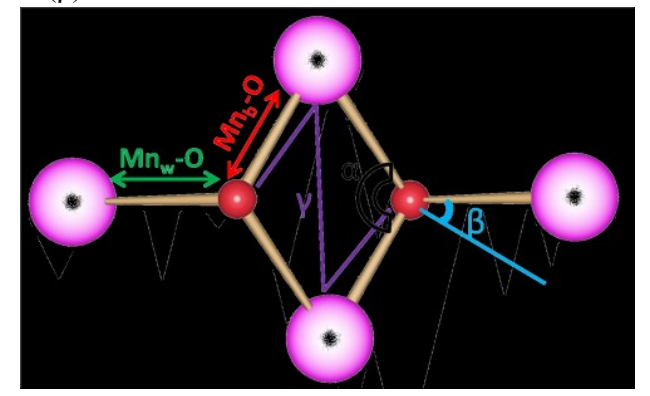

Figure 9. Structural parameters that can affect the exchange interaction.

Class 1: $\mathrm{Mn}_{b}-\mathrm{O}$ distance correlation: This correlation is developed by varying the $\mathrm{Mn}_{\mathrm{b}} \mathrm{O}$ distances from $1.7 \AA$ to $2.3 \AA$. While $J_{w w}$ is found to be unaltered, the $J_{\mathrm{bb}}$ and $J_{\mathrm{wb}}$ values are affected with longer distances yielding less antiferromagnetic $J$ values. It is found that the body-body interaction $\left(J_{\mathrm{bb}}\right)$ depends mainly on the $\mathrm{Mn}$-O distance ($18.8 \mathrm{~cm}^{-1}$ to $0.8 \mathrm{~cm}^{-1}$ between $1.7-2.5 \AA$ ). For shorter $\mathrm{Mn}_{\mathrm{b}}-\mathrm{O}$ distances, the $J_{\mathrm{bb}}$ interaction give rise to strong antiferromagnetic behavior (see Figure 10a). As the $\mathrm{Mn}_{\mathrm{b}} \mathrm{O}$ distance is correlated to the $\mathrm{d}_{\mathrm{z}}^{2}$ orbital interaction, shortening this distance will enhance the overlap with both the $\mathrm{Mn}^{\mathrm{II}}$ and $\mathrm{Mn}^{\mathrm{III}}$ ions leading to antiferromagnetic coupling. The wing-body $\left(J_{\mathrm{wb}}\right)$ interaction is marginally affected by the $\mathrm{Mnb}-\mathrm{O}$ distance parameter $\left(-1.39 \mathrm{~cm}^{-1}\right.$ to $\left.1.75 \mathrm{~cm}^{-1}\right)$.

Overlapping the experimentally determined fits $\left(J_{\mathrm{bb}}\right.$ and $\left.J_{\mathrm{wb}}\right)$ on the computed correlation reveals, however, little variation in the $\mathrm{Mn}_{\mathrm{b}} \mathrm{O}$ parameter among the family of structures studied here and reported earlier. However, we would like to note that the correlation is developed by fixing all the geometric parameters to that of complex $\mathbf{3}$, except for varying the $\mathrm{Mn}_{\mathrm{b}} \mathrm{O}$ distances, while experimental structures reflect changes on all structural parameters.

$M n_{w}-O$ distance correlation: This correlation is developed by varying the $\mathrm{Mn}_{\mathrm{w}}-\mathrm{O}$ distances from $1.9 \AA$ to $2.7 \AA$ (see Figure 10b). While $J_{\mathrm{ww}}$ and $J_{\mathrm{bb}}$ is found to be nearly unaltered, the $J_{\mathrm{wb}}$ parameter is affected, with longer distances yielding less ferromagnetic $J$ values (+7 to $-1 \mathrm{~cm}^{-1}$ ). Again overlapping the experimentally determined fits on the computed correlation reveals some $\mathrm{Mn}_{\mathrm{w}} \mathrm{O}$ structural variation. $M n_{b}-O-M n_{b}$ angle correlation: This angular correlation is developed by varying the $\mathrm{Mn}_{\mathrm{b}}-\mathrm{O}-\mathrm{Mn}_{\mathrm{b}}$ angle from 80 to $120^{\circ}$. For the $J_{\mathrm{bb}}$ and $J_{\mathrm{wb}}$ interaction the $J$ values vary between $-28.9 \mathrm{~cm}^{-1}$ to $2.62 \mathrm{~cm}^{-1}$ and $\mathrm{xx}$ to $\mathrm{xx} \mathrm{cm}^{-1}$, respectively, as the angle is changed. At smaller $\mathrm{Mn}_{\mathrm{b}}-\mathrm{O}-$ $\mathrm{Mn}_{\mathrm{b}}$ angles the $J_{\mathrm{bb}}$ interaction gives rise to strong antiferromagnetic behavior (see Figure 10c). As the angle increases the interaction becomes less antiferromagnetic due to the diminishing overlap between the magnetic orbitals leading to a smaller antiferromagnetic contribution. The $J_{\mathrm{ww}}$ parameter is found to be insensitive to the Mn-O-Mn angle.

$\mathrm{Mn}_{b}-\mathrm{O}-\mathrm{Mn}_{b}-\mathrm{O}$ angle $(\gamma)$ : This correlation is developed by varying the $\gamma$ angle from 0 to 35 degrees. For small $\mathrm{Mn}_{b}-\mathrm{O}-\mathrm{Mn}_{\mathrm{b}}-\mathrm{O}$ angles $(0-$ $10^{\circ}$ ), the $J_{b b}, J_{\mathrm{wb}}$ and $J_{w w}$ interactions are ferromagnetic. It is found that all three $J$ values are sensitive to the angle such that larger $\gamma$ values yield increasingly antiferromagnetic $J_{\mathrm{wb}}$ and $J_{\mathrm{bb}}$ and increasingly ferromagnetic $J_{\mathrm{ww}}$ interactions (see Figure 10d).

$M n-O-O$ angle $(\beta)$ : This parameter does not influence $J_{b b}$ or $J_{w w}$, however, influences the $J_{w b}$ parameter. At angles $>82^{\circ}$ the interaction becomes increasingly ferromagnetic before plateauing above $100^{\circ}$.

From the correlation it is found that the wing-wing interaction $\left(J_{\mathrm{ww}}\right)$ is not affected by geometrical changes and remains weak for the whole range of investigated geometrical parameters, except for the $\gamma$ parameter where it is found to vary. From the data we can therefore conclude that the magnetic exchange interactions $\left(J_{b b}\right.$ and $\left.J_{w b}\right)$ of Class 1 complexes are predominantly affected by the $\mathrm{Mn}_{\mathrm{b}}-\mathrm{O}$ bond distance and the $\mathrm{Mn}_{\mathrm{b}}-\mathrm{O}-\mathrm{Mn}_{\mathrm{b}}$ bond angle, whereas the $\mathrm{Mn}_{\mathrm{w}}-\mathrm{O}$ bond distance, the dihedral $\mathrm{Mn}_{b}-\mathrm{O}-\mathrm{Mn}_{\mathrm{b}}-\mathrm{O}$ angle $(\gamma)$ and the out of shift plane parameters play a minor role in influencing the magnetic exchange parameters (Figure 10b and 10d).

Class 2: Similar magneto-structural correlations are also developed for complex 9 and indicate that the body-body interaction $\left(J_{\mathrm{bb}}\right)$ depends mainly on the $\mathrm{Mn}_{\mathrm{b}}-\mathrm{O}-\mathrm{Mn}_{\mathrm{b}}$ angle $\left(-6.62 \mathrm{~cm}^{-1}\right.$ to $-0.13 \mathrm{~cm}^{-1}$, between $\left.80-120^{\circ}\right)$. At the largest and smallest $\mathrm{Mn}_{\mathrm{b}}-\mathrm{O}-\mathrm{Mn}_{\mathrm{b}}$ angles, the $J_{\mathrm{bb}}$ interaction gives rise to the strongest antiferromagnetic value (see Figure $11 \mathrm{c})$. The $J_{\mathrm{wb}}$ and $J_{\mathrm{ww}}$ interactions are not affected by the $\mathrm{Mn}_{\mathrm{b}}$ $\mathrm{O}-\mathrm{Mn}_{\mathrm{b}}$ angle. The wing-body interaction $\left(J_{w b}\right)$ is affected by the $\mathrm{Mn}_{\mathrm{w}}-\mathrm{O}$ bond distance and the dihedral $\mathrm{Mn}_{b}-\mathrm{O}-\mathrm{Mn}_{b}-\mathrm{O}$ angle $(\gamma)$ (see Figure $11 \mathrm{~b}$ and $11 \mathrm{~d}$ ). At larger $\mathrm{Mn}_{\mathrm{b}}-\mathrm{O}-\mathrm{Mn}_{\mathrm{b}}-\mathrm{O}$ angles, the $J_{\mathrm{wb}}$ interaction shows antiferromagnetic coupling and the $J_{\mathrm{ww}}$ shows moderate ferromagnetic behavior. Comparatively the other structural parameters $\mathrm{Mn}_{\mathrm{b}}-\mathrm{O}$ and the out of plane shift parameter (see Figure 11a and 11e) do not affect the $J_{w b}$ values as much as the $\mathrm{Mn}_{\mathrm{b}}-\mathrm{O}-\mathrm{Mn} \mathrm{b}$ bond angle, the $\mathrm{Mn}_{\mathrm{w}}-\mathrm{O}$ bond distance and the dihedral $\mathrm{Mn}_{\mathrm{b}}-\mathrm{O}-\mathrm{Mn} \mathrm{n}_{\mathrm{b}} \mathrm{O}$ angle. 
Table 5. Average bond distances $(\AA)$ and bond angles $\left(^{\circ}\right)$ that can affect the exchange interactions of the $\left\{\mathrm{Mn}_{4}\right\}$ complexes. (see Figure 9)

\begin{tabular}{|c|c|c|c|c|c|}
\hline Complex & $\mathbf{M n}_{\mathbf{b}}-\mathbf{O}$ & $\mathbf{M n}_{\mathbf{w}}-\mathbf{O}$ & $\boldsymbol{\alpha}$ & $\boldsymbol{\gamma}$ & $\boldsymbol{\beta}$ \\
\hline $\mathbf{1}$ & 2.11 & 2.27 & 99.4 & 0 & 102.8 \\
\hline $\mathbf{2}$ & 2.12 & 2.35 & 100.1 & 0 & 100.7 \\
\hline $\mathbf{3}$ & 2.09 & 2.32 & 99.3 & 0 & 99.1 \\
\hline $\mathbf{4}$ & 2.10 & 2.27 & 96.4 & 0 & 100.8 \\
\hline $\mathbf{5}$ & 2.09 & 2.31 & 97.5 & 0 & 98.2 \\
\hline $\mathbf{6}$ & 2.09 & 2.39 & 99.9 & 0 & 99.7 \\
\hline $\mathbf{7}$ & 2.11 & 2.26 & 101.1 & 0 & 100.1 \\
\hline $\mathbf{8}$ & 2.10 & 2.46 & 100.1 & 0 & 98.6 \\
\hline $\mathbf{9}$ & 2.35 & 1.94 & 100.9 & 0 & 106.6 \\
\hline $\mathbf{1 0}$ & 2.33 & 1.95 & 95.6 & 2.1 & 112.6 \\
\hline $\mathbf{1 1}$ & 2.33 & 1.92 & 102.0 & 0 & 108.1 \\
\hline $\mathbf{1 2}$ & 2.43 & 1.93 & 99.9 & 0 & 107.4 \\
\hline
\end{tabular}

To gain further insight into the correlations developed for complexes 3 and 9, we have analyzed the structural parameters and the corresponding $J$ values observed for other complexes. In Class 1 , the $J_{\mathrm{bb}}$ parameter mainly varies by changing the $\mathrm{Mn}_{b}-\mathrm{O}$ distance and the $\mathrm{Mn}_{b}-\mathrm{O}-\mathrm{Mn}_{\mathrm{b}}$ angle. The $\mathrm{Mn}_{b}-\mathrm{O}$ distance and the $\mathrm{Mn}_{b}-\mathrm{O}-\mathrm{Mn}_{\mathrm{b}}$ angle for Class 1 complexes are $\sim 2.1 \AA$ and $96.3-101.1^{\circ}$, respectively. As the $\mathrm{Mn} b-\mathrm{O}$ distance is similar for all complexes then this suggests that this parameter is not causing the differences found in the $J$ analysis for Class 1 compounds. The variation is therefore primarily due to the changing $\mathrm{Mn}_{b}-\mathrm{O}-\mathrm{Mn}_{\mathrm{b}}$ angle. The correlations suggest moderate ferromagnetic behavior for $J_{\mathrm{bb}}$ for these structural parameters which is in broad agreement with the extracted experimental $J$ values. The $J_{\mathrm{wb}}$ interaction on the other hand is expected to be influenced by $\mathrm{Mn}_{\mathrm{b}}-\mathrm{O}, \mathrm{Mn}_{\mathrm{w}}-\mathrm{O}$ distances and the $\mathrm{Mn}_{\mathrm{b}}-\mathrm{O}-\mathrm{Mn}_{\mathrm{b}} \mathrm{O}$ dihedral angle $(\gamma)$. The developed correlation revealed a stronger dependence of $J_{\mathrm{wb}}$ on the $\mathrm{Mn}_{\mathrm{w}}-\mathrm{O}$ distance and the $\mathrm{Mn}-\mathrm{O}-\mathrm{Mn}_{\mathrm{b}} \mathrm{O}$ dihedral angle. However, these two parameters are nearly constant for all the structures reported (See experimental points on Figure 10). On the other hand, a moderate dependence on the $J$ parameter is noted for the $\mathrm{Mn}_{b}-\mathrm{O}-\mathrm{Mn}_{\mathrm{b}}$ bond angle. As this parameter is found to vary among the structures studied, this parameter rationalizes the observed variation in the $J_{\mathrm{wb}}$ values. The correlations also show that the wing-wing interaction $\left(J_{\mathrm{ww}}\right)$ is not affected significantly by any of the structural parameters, revealing very weak exchange interactions which is in excellent agreement with the calculated $J_{\mathrm{ww}}$ for all Class 1 complexes.

In Class 2, the structural parameter which is found to affect the $J_{\mathrm{bb}}$ value is the $\mathrm{Mn}_{\mathrm{b}}-\mathrm{O}-\mathrm{Mn}_{\mathrm{b}}$ angle, which ranges from $95-102^{\circ}$ for 9 12. Our correlation suggests that antiferromagnetic behavior is expected and will be greater at larger and smaller angles (boundaries). This is in good agreement with the calculated $J_{\mathrm{bb}}$ values for all Class 2 complexes, except 12, which is found at the optimum angle between the smaller and larger angle resulting in ferromagnetic behavior. The $J_{w b}$ interaction is affected by all parameters, except the $\mathrm{Mn}_{\mathrm{b}^{-}}$ $\mathrm{O}$ distance. It is found however, that the structural parameters do not vary significantly and the weak ferromagnetic exchange (weak antiferromagnetic for 12) extracted from the fits agree nicely with the correlations.

The $J_{\mathrm{ww}}$ interactions are affected by the dihedral angle $(\gamma)$ which is in the range of $0-2.1^{\circ}$. The dihedral angle correlation suggests that the wing-wing interaction $\left(J_{\mathrm{ww}}\right)$ shows only a weak exchange interaction up to $2.1^{\circ}$ which is in excellent agreement with the calculated $J_{\mathrm{ww}}$ for all Class 2 complexes.

In summary, the analysis of the dependence of the exchange interactions on the structural parameters signifies that the body-body interaction is strongly dependent on the $\mathrm{Mn}_{b}-\mathrm{O}-\mathrm{Mn}_{b}$ angle and the wing-body interactions is strongly dependent on $\mathrm{Mn}_{\mathrm{b}}-\mathrm{O}-\mathrm{Mn}_{\mathrm{b}}-\mathrm{O}$ dihedral angle for both Class 1 and 2 causing variations in the $J$ magnetic exchange parameters and therefore the observed magnetic properties.

To validate our developed correlations, we have compared the reported (Class 1 , See Table 3 ) $J_{\mathrm{bb}}$ values with the $\mathrm{Mn}_{b}-\mathrm{O}-\mathrm{Mn}_{\mathrm{b}}$ angle and the $J_{\mathrm{wb}}$ values with the $\mathrm{Mn}_{\mathrm{b}}-\mathrm{O}-\mathrm{Mn}_{\mathrm{b}}-\mathrm{O}$ angle (See Figure 9c and $9 \mathrm{~d})$. Our predictions are in good agreement with these previously reported $J$ values. 

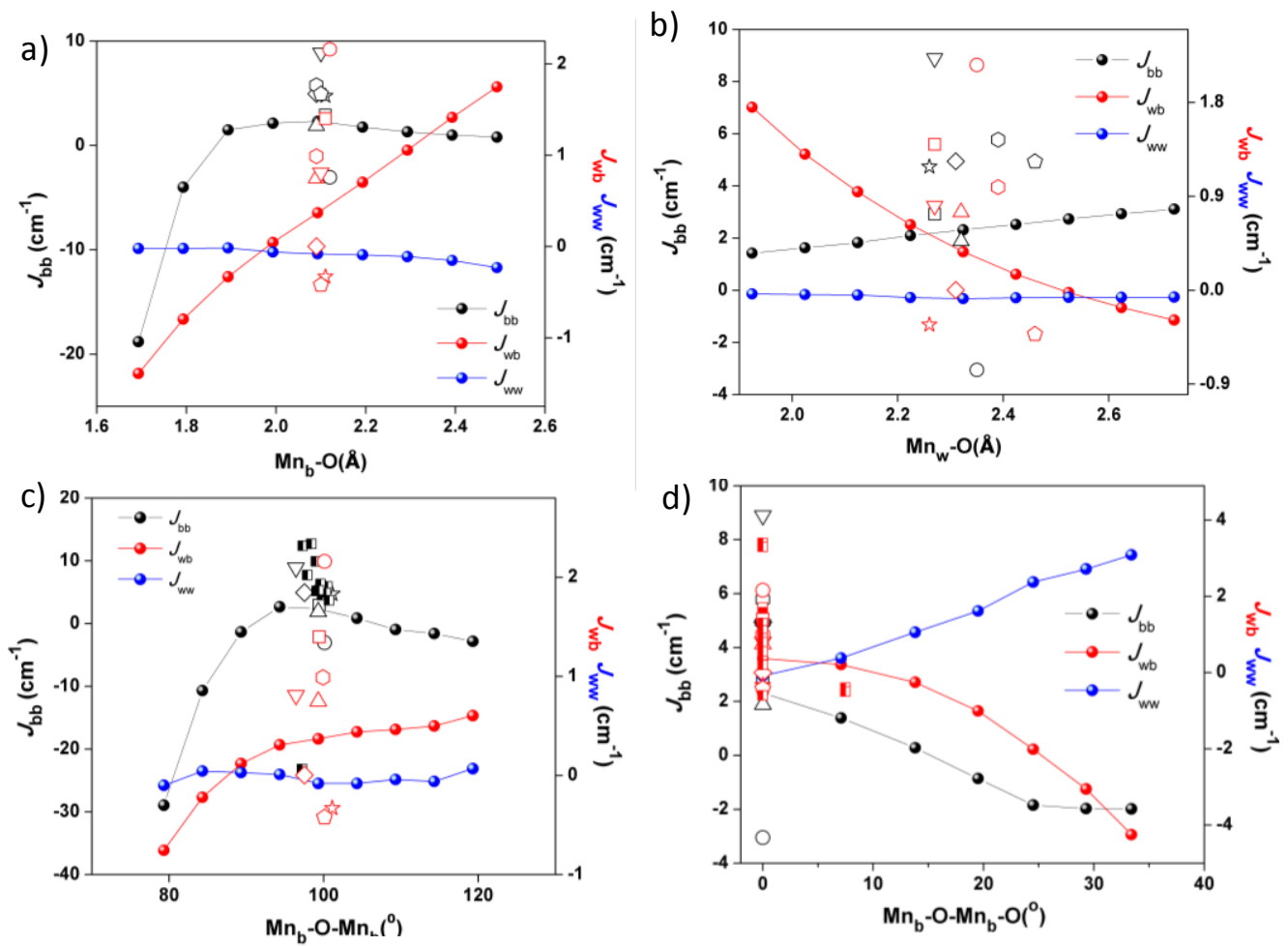

e)

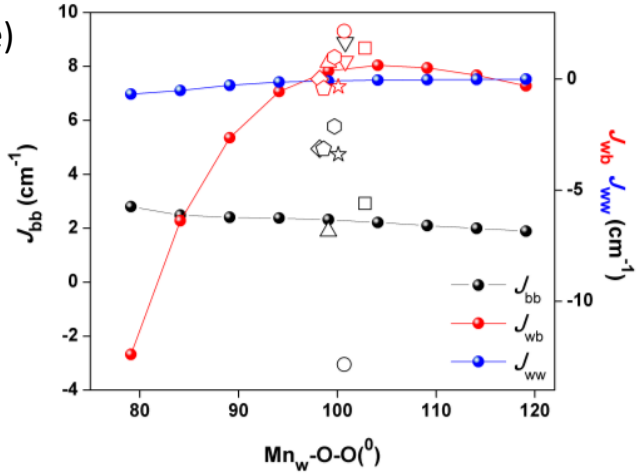

Figure 10. Structural parameters that affect the exchange coupling constants a) Mnb-O bond distance b) $\mathrm{Mn}_{\mathrm{w}}-\mathrm{O}$ bond distance c) Mnb-O$\mathrm{Mn}_{\mathrm{b}}$ bond angle, $\mathrm{d}$ ) the dihedral $\mathrm{Mn}_{\mathrm{b}}-\mathrm{O}-\mathrm{Mn}_{\mathrm{b}} \mathrm{O}$ angle e) out-of-plane shift of the $\mathrm{Mn}_{\mathrm{w}}$ atoms. The black $\left(J_{\mathrm{bb}}\right)$ and red $\left(J_{\mathrm{wb}}\right)$ open symbols are experimental $J$ values of $\mathbf{1}(\square), \mathbf{2}(\mathrm{O}), \mathbf{3}(\Delta), \mathbf{4}(\nabla), \mathbf{5}(\diamond), \mathbf{6}(\square), 7(\dot{\xi})$ and $\mathbf{8}(\Delta)$. The half shaded squares in (c) and (d) are $J_{\mathrm{bb}}$ and $J_{\mathrm{wb}}$ values of reported $\left\{\mathrm{Mn}_{2}{ }_{2} \mathrm{Mn}_{2}{ }_{2}\right\}$ complexes, respectively. (CLASS 1). 

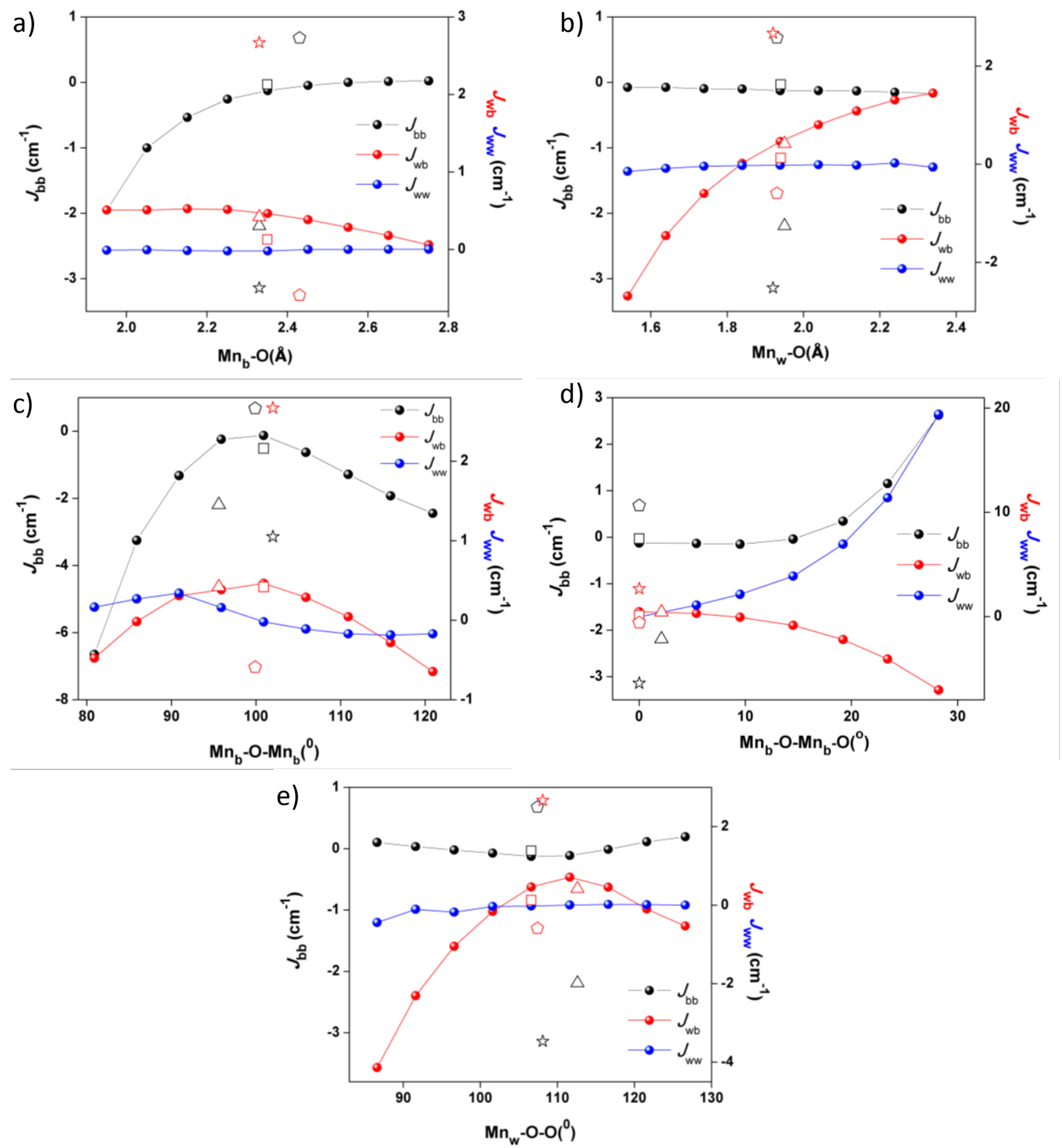

Figure 11. Structural parameters that affect the exchange coupling constants with the a) $\mathrm{Mn}_{\mathrm{b}}-\mathrm{O}$ bond distance b) $\mathrm{Mn}_{\mathrm{w}}-\mathrm{O}$ bond distance c) $\mathrm{Mn}_{\mathrm{b}}-\mathrm{O}-\mathrm{Mn} \mathrm{b}$ bond angle, d) the dihedral $\mathrm{Mn}_{\mathrm{b}} \mathrm{O}-\mathrm{Mn} \mathrm{b}-\mathrm{O}$ angle e) out-of-plane shift of the $\mathrm{Mn}_{\mathrm{w}}$ atoms. The black $\left(J_{\mathrm{bb}}\right)$ and red $\left(J_{\mathrm{wb}}\right)$ open symbols are experimental $J$ values of $9(\square), \mathbf{1 0}(\Delta), \mathbf{1 1}(\dot{\star})$ ) and 12( $\triangle)$. (CLASS 2). 


\section{CONCLUSIONS}

We have successfully synthesized and studied twelve mixed valent $\left\{\mathrm{Mn}_{2}{ }_{2} \mathrm{Mn}^{\mathrm{III}}{ }_{2}\right\}$ manganese complexes which display a butterfly metallic core. These compounds are classified by the position of the ions in the metallic core. Two distinct structural types are observed and denoted as Class 1 and 2. Class 1 compounds place the Mn(III) ions in the body positions of the "butterfly" metallic core, while the $\mathrm{Mn}(\mathrm{II})$ ions occupy the outer wing sites. Class 2 complexes display the reverse arrangement of ions, with the $\mathrm{Mn}(\mathrm{II})$ sites in the body positions and the $\mathrm{Mn}(\mathrm{III})$ ions occupying the outer wing sites. Magnetic measurements revealed differing magnetic exchange coupling parameters for each complex and compounds 1 - 9 and $\mathbf{1 1}$ display slow magnetization relaxation suggesting that they are single-molecule magnets.

In-depth, magnetic analysis of the twelve complexes revealed the following. In general, the extracted experimentally fitted and the DFT calculated $J$ values yield the following conclusions: (i) DFT can be used as an excellent tool for determining the nature of magnetic exchange interactions within polynuclear manganese based complexes. (ii) From both experiment and theory it is found the wing-body $J_{\mathrm{wb}}$ coupling parameter is moderately ferromagnetic in nature for all complexes $\left(-0.45-1.37 \mathrm{~cm}^{-1}\right)$, except for 7,8 (experimental fit) and 12 (DFT and fit) (see Table 1); (iii) The body-body interactions $\left(J_{\mathrm{bb}}\right)$ are generally ferromagnetic for Class 1 and antiferromagnetic for Class 2. This $J_{b b}$ pathway $\left(\mathrm{Mn}^{\mathrm{III}}-\mathrm{Mn}^{\mathrm{III}}\right)$ is the also generally the strongest interaction for Class 1 complexes $\left(-0.06-+2.32 \mathrm{~cm}^{-1}\right)$. (iv) The wing-wing $\left(J_{\mathrm{ww}}\right)$ coupling constant, determined via DFT only, is found to show weak antiferromagnetic values for all the complexes, except in $\mathbf{1 0}$ and 12, which are weakly ferromagnetic; (v) The spin ground state is generally found to be larger for Class 1, than Class 2. This due to the fact that some of the body-body $\left\{\mathrm{Mn}^{\mathrm{II}}-\mathrm{Mn}^{\mathrm{II}}\right\}$ interactions for Class 2 complexes are weaker than the $\left\{\mathrm{Mn}^{\mathrm{III}}-\mathrm{Mn}^{\mathrm{II}}\right\}$ wingbody interactions leading to dominant antiferromagnetic coupling and a smaller ground state $S$ value. (vi) DFT calculations yield negative $D$ values for all complexes. This suggests that if the spin ground state is large, slow relaxation of the magnetization will be observed. The magnitude of $D$ was also found to be significantly influenced by the electron donating/withdrawing substituents of the ligands.

In line with the theoretical predictions, complexes 1, 2, 3, 6 and 9 display clear SMM behavior, displaying peak maxima in the $\chi_{M}$ " vs $T$ plots, allowing for the determination of the anisotropy barrier $\left(U_{e f f}\right)$. The order of the size of the energy barrier is $\mathbf{3} \sim \mathbf{6}>\mathbf{1}>\mathbf{2} \sim 9$. The DFT computed energy barriers (taking into account the computed $D$ and the ground state $S$ value) are also in line with the experimental value for $\mathbf{2 , 3}$ and $\mathbf{6}$ and slightly underestimated for $\mathbf{1}$ and $\mathbf{9}$ (see Table ST5). Our calculations indicate that by attaching the electron withdrawing and donating substituent's to the ligands, one can alter the nature of the magnetic exchange interaction, $J$, and thus the ground state and importantly, also, the anisotropy. The Class 1 complexes possessing $\left\{\mathrm{Mn}^{\mathrm{III}}(\mathrm{OR})_{2}\right\}$ interactions at the body positions are superior compared to their $\mathrm{Mn}^{\mathrm{II}}$ counterparts as these body-body interactions are found to control the sign and strength of the $J$ parameters as well as the magnetic anisotropy. The developed magneto-structural correlations suggest possible future ways to enhance the $J$ 's by fine tuning the $\mathrm{Mn}_{\mathrm{b}}-\mathrm{O}-\mathrm{Mn}_{\mathrm{b}}$ and $\mathrm{Mn}_{\mathrm{b}}-\mathrm{O}-\mathrm{Mn}_{\mathrm{b}}-\mathrm{O}$ parameters in these $\left\{\mathrm{Mn}_{4}\right\}$ butterfly systems.

\section{ASSOCIATED CONTENT}

\section{Supporting Information}

Electronic Supplementary Information (ESI) available: Crystallographic data in CIF format; Table ST1, crystallographic data; Tables ST2, bond valence sum values; Table ST3, Bond lengths and angles; Tables ST4,Computed ZFS parameters; Table ST5, Energy barrier values; Tables ST6, computed ground and $1^{\text {st }}$ excited spin state values; Table ST7, spin configurations employed for extracting $J$ values; Figure SF1, SF2, Molecular structures of $\mathbf{2}-\mathbf{8}$ and $\mathbf{1 0}$ - 12; Figure SF3-SF6, packing diagram of 1 - 12; Figure SF7-SF14, AC susceptibility plots; Figure SF15, Arrhenius plots; Figure SF16SF21,susceptibility plots of $\mathbf{1} \mathbf{- 1 2}$; Figure SF22, orbital orientations. This material is available free of charge via the Internet at http://pubs.acs.org. Compounds $\mathbf{1 - 8}$ and $\mathbf{1 0}$ correlate to CCDC Nos. 1483120-1483128, which can be obtained free of charge from the Cambridge Crystallographic Data Center via www.ccdc.cam.ac.uk/data_request/cif.

\section{AUTHOR INFORMATION}

\section{Corresponding Author}

keith.murray@monash.edu and rajaraman@chem.iitb.ac.in.

\section{Notes}

The authors declare no competing financial interests.

\section{ACKNOWLEDGEMENTS}

GR would like to acknowledge the financial support from DST India, and IIT Bombay for the high performance computing facility. KRV and GR acknowledge the C-DAC's Supercomputing resources (PARAM Yuva-II). KRV is thankful to the IITB-Monash Research Academy for a PhD studentship. GR and KSM acknowledge the support of an Australia-India Strategic Research Fund (AISRF) grant.

\section{REFERENCES}

1. (a) Murray, K. S., The Magnetochemistry of Homo-and Hetero-Tetranuclear First-Row d-Block Complexes. Sykes, A. G., Ed. Academic Press: 1995; Vol. Volume 43, pp 261-358. (b) Albela, B.; El Fallah, M. S.; Ribas, J.; Folting, K.; Christou, G.; Hendrickson, D. N., Two New Mixed-Valence Manganese Complexes of Formula [Mn4O2(X-benzoato)7(bpy)2] (X = 2-Cl, 2-Br) and the Crystal Structure of the 2-Cl Complex: Ground-State Spin Variability in the [Mn4O2]7+ Complexes. Inorg. Chem. 2001, 40, 1037-1044. (c) Yang, C.-I.; Lee, G.-H.; Wur, C.-S.; Lin, J. G.; Tsai, H.-L., Syntheses, structures and single-molecule magnetic behaviors of two dicubane Mn4 complexes. Polyhedron 2005, 24, 2215-2221. (d) Yoo, J.; Yamaguchi, A.; Nakano, M.; Krzystek, J.; Streib, W. E.; Brunel, L.-C.; Ishimoto, H.; Christou, G.; Hendrickson, D. N., Mixed-Valence Tetranuclear Manganese Single-Molecule Magnets. Inorg. Chem. 2001, 40, 4604-4616. (e) Lecren, L.; Li, Y.-G.; Wernsdorfer, W.; Roubeau, O.; Miyasaka, H.; Clérac, R., [Mn4(hmp)6(CH3CN)2(H2O)4]4+: A new single-molecule magnet with the highest blocking temperature in the Mn4/hmp family of compounds. Inorg. Chem. Commun. 2005, 8, 626-630. (f) Lecren, L.; Roubeau, O.; Li, Y.-G.; Le Goff, X. F.; Miyasaka, H.; Richard, F.; Wernsdorfer, W.; Coulon, C.; Clerac, R., One-dimensional coordination polymers of antiferromagnetically-coupled [Mn4] single-molecule magnets. Dalton Trans. 2008, 755-766. (g) Yang, E.-C.; Harden, N.; Wernsdorfer, W.; Zakharov, L.; Brechin, E. K.; Rheingold, A. L.; Christou, G.; Hendrickson, D. N., Mn4 singlemolecule magnets with a planar diamond core and $\mathrm{S}=9$. Polyhedron 2003, 22, 1857-1863. (h) Langley, S. K.; Chilton, N. F.; Massi, M.; Moubaraki, B.; Berry, K. J.; Murray, K. S., Synthesis and 
characterization of homo- and heterovalent tetra- hexa- hepta- and decanuclear manganese clusters using pyridyl functionalized [small beta]-diketone, carboxylate and triethanolamine ligands. Dalton Trans. 2010, 39, 7236-7249. (i) Langley, S. K.; Chilton, N. F.; Moubaraki, B.; Murray, K. S., Structure and magnetic exchange in heterometallic $3 \mathrm{~d}-3 \mathrm{~d}$ transition metal triethanolamine clusters. Dalton Trans. 2012, 41, 1033-1046. (j) Wittick, L. M.; Jones, L. F.; Jensen, P.; Moubaraki, B.; Spiccia, L.; Berry, K. J.; Murray, K. S., New mixed-valence MnII2MnIII2 clusters exhibiting an unprecedented $\mathrm{MnII} / \mathrm{III}$ oxidation state distribution in their magnetically coupled cores. Dalton Trans. 2006, 1534-1543. (k) Lecren, L.; Roubeau, O.; Coulon, C.; Li, Y.-G.; Le Goff, X. F.; Wernsdorfer, W.; Miyasaka, H.; Clérac, R., Slow Relaxation in a One-Dimensional Rational Assembly of Antiferromagnetically Coupled [Mn4] Single-Molecule Magnets. J. Am. Chem. Soc. 2005, 127, 17353-17363. (1) Yoo, J.; Brechin, E. K.; Yamaguchi, A.; Nakano, M.; Huffman, J. C.; Maniero, A. L.; Brunel, L.-C.; Awaga, K.; Ishimoto, H.; Christou, G.; Hendrickson, D. N., Single-Molecule Magnets: A New Class of Tetranuclear Manganese Magnets. Inorg. Chem. 2000, 39, 3615-3623. (m) Miyasaka, H.; Nakata, K.; Lecren, L.; Coulon, C.; Nakazawa, Y.; Fujisaki, T.; Sugiura, K.-i.; Yamashita, M.; Clérac, R., Two-Dimensional Networks Based on Mn4 Complex Linked by Dicyanamide Anion: From SingleMolecule Magnet to Classical Magnet Behavior. J. Am. Chem. Soc. 2006, 128, 3770-3783. (n) K. Brechin, E.; C. Huffman, J.; Christou, G.; Yoo, J.; Nakano, M.; N. Hendrickson, D., A new class of singlemolecule magnets: mixed-valent $[\mathrm{Mn} 4(\mathrm{O} 2 \mathrm{CMe}) 2(\mathrm{Hpdm}) 6][\mathrm{ClO} 4] 2$ with an $\mathrm{S}=8$ ground state. Chem. Commun. 1999, 783-784. (o) Wittick, L. M.; Murray, K. S.; Moubaraki, B.; Batten, S. R.; Spiccia, L.; Berry, K. J., Synthesis, structure and magnetism of new single molecule magnets composed of MnII2MnIII2 alkoxo-carboxylate bridged clusters capped by triethanolamine ligands. Dalton Trans. 2004, 1003-1011. (p) Yoo, J.; Wernsdorfer, W.; Yang, E.-C.; Nakano, M.; Rheingold, A. L.; Hendrickson, D. N., OneDimensional Chain of Tetranuclear Manganese Single-Molecule Magnets. Inorg. Chem. 2005, 44, 3377-3379. (q) Hiraga, H.; Miyasaka, H.; Nakata, K.; Kajiwara, T.; Takaishi, S.; Oshima, Y.; Nojiri, H.; Yamashita, M., Hybrid Molecular Material Exhibiting Single-Molecule Magnet Behavior and Molecular Conductivity. Inorg. Chem. 2007, 46, 9661-9671. (r) Miyasaka, H.; Nakata, K.; Sugiura, K.-i.; Yamashita, M.; Clérac, R., A Three-Dimensional Ferrimagnet Composed of Mixed-Valence Mn4 Clusters Linked by an $\{\mathrm{Mn}[\mathrm{N}(\mathrm{CN}) 2] 6\} 4-$ Unit. Angew. Chem. Int. Ed. 2004, 43, 707711. (s) Lecren, L.; Wernsdorfer, W.; Li, Y.-G.; Roubeau, O.; Miyasaka, H.; Clérac, R., Quantum Tunneling and Quantum Phase Interference in a [MnII2MnIII2] Single-Molecule Magnet. J. Am. Chem. Soc. 2005, 127, 11311-11317. (t) Lu, Z.; Fan, C., A novel tetranuclear MnII2MnIII2 cluster [Mn4(hmp)6(N3)4]: Synthesis, crystal structure and magnetic properties. Inorg. Chem. Commun. 2011, 14, 1329-1332. (u) Ako, A. M.; Mereacre, V.; Hewitt, I. J.; Clerac, R.; Lecren, L.; Anson, C. E.; Powell, A. K., Enhancing single molecule magnet parameters. Synthesis, crystal structures and magnetic properties of mixed-valent Mn4 SMMs. J. Mater. Chem. 2006, 16, 2579-2586.

2. (a) Wang, M.; Ma, C.-B.; Yuan, D.-Q.; Wang, H.-S.; Chen, C.-N.; Liu, Q.-T., Synthesis and Characterization of a Family of Penta- and Tetra-Manganese(III) Complexes Derived from an Assembly System Containing tert-Butylphosphonic Acid. Inorg. Chem. 2008, 47, 5580-5590. (b) Wemple, M. W.; Tsai, H.-L.; Wang, S.; Claude, J. P.; Streib, W. E.; Huffman, J. C.; Hendrickson, D. N.; Christou, G., Tetranuclear and Octanuclear Manganese Carboxylate Clusters: Preparation and Reactivity of
(NBun4)[Mn4O2(O2CPh)9(H2O)] and Synthesis of (NBun4)2[Mn8O4(O2CPh)12(Et2mal)2(H2O)2] with a "LinkedButterfly" Structure. Inorg. Chem. 1996, 35, 6437-6449. (c) Ruettinger, W.; Yagi, M.; Wolf, K.; Bernasek, S.; Dismukes, G. C., O2 Evolution from the Manganese-Oxo Cubane Core Mn4O46+: A Molecular Mimic of the Photosynthetic Water Oxidation Enzyme? J. Am. Chem. Soc. 2000, 122, 10353-10357. (d) Hendrickson, D. N.; Christou, G.; Schmitt, E. A.; Libby, E.; Bashkin, J. S.; Wang, S.; Tsai, H. L.; Vincent, J. B.; Boyd, P. D. W., Photosynthetic water oxidation center: spin frustration in distorted cubane MnIVMnIII3 model complexes. J. Am. Chem. Soc. 1992, 114, 2455-2471.

3. (a) Gatteschi, D.; Sessoli, R., Quantum Tunneling of Magnetization and Related Phenomena in Molecular Materials. Angew. Chem. Int. Ed. 2003, 42, 268-297. (b) Sessoli, R.; Gatteschi, D.; Caneschi, A.; Novak, M. A., Magnetic Bistability in a Metal-Ion Cluster. Nature 1993, 365, 141-143. (c) Sessoli, R.; Tsai, H. L.; Schake, A. R.; Wang, S.; Vincent, J. B.; Folting, K.; Gatteschi, D.; Christou, G.; Hendrickson, D. N., High-spin molecules: $\left[\mathrm{Mn}_{12} \mathrm{O}_{12}\left(\mathrm{O}_{2} \mathrm{CR}\right)_{16}\left(\mathrm{H}_{2} \mathrm{O}\right)_{4}\right]$. J. Am. Chem. Soc. 1993, 115, 1804-1816. 4. (a) D. Gatteschi; R. Sessoli; Villain, J., Molecular Nanomagnets. Oxford University Press, Oxford: 2006. (b) Molecular spintronics and quantum computing. J. Mater. Chem. 2009, 19, 16701671. (c) Leuenberger, M. N.; Loss, D., Quantum computing in molecular magnets. Nature 2001, 410, 789-793. (d) Bogani, L.; Wernsdorfer, W., Molecular spintronics using single-molecule magnets. Nat. Mater. 2008, 7, 179-186. (e) Evangelisti, M.; Brechin, E. K., Recipes for enhanced molecular cooling. Dalton Trans. 2010, 39, 4672-4676. (f) Karotsis, G.; Kennedy, S.; Teat, S. J.; Beavers, C. M.; Fowler, D. A.; Morales, J. J.; Evangelisti, M.; Dalgarno, S. J.; Brechin, E. K., [MnIII4LnIII4] Calix[4]arene Clusters as Enhanced Magnetic Coolers and Molecular Magnets. J. Am. Chem. Soc. 2010, 132, 12983-12990.

5. Roubeau, O.; Clérac, R., Rational Assembly of High-Spin Polynuclear Magnetic Complexes into Coordination Networks: the Case of a [Mn4] Single-Molecule Magnet Building Block. Eur. J. Inorg. Chem. 2008, 2008, 4325-4342.

6. (a) McCusker, J. K.; Vincent, J. B.; Schmitt, E. A.; Mino, M. L.; Shin, K.; Coggin, D. K.; Hagen, P. M.; Huffman, J. C.; Christou, G.; Hendrickson, D. N., Molecular spin frustration in the [Fe4O2]8+ core: synthesis, structure, and magnetochemistry of tetranuclear iron-oxo complex [Fe4O2(O2CR)7(bpy)2](C1O4) $(\mathrm{R}=$ $\mathrm{Me}, \mathrm{Ph}$ ). J. Am. Chem. Soc. 1991, 113, 3012-3021. (b) Hriljac, J. A.; Harris, S.; Shriver, D. F., Protonation and bonding in heterometallic butterfly carbide clusters. Inorg. Chem. 1988, 27, 816-821. (c) Boudalis, A. K.; Lalioti, N.; Spyroulias, G. A.; Raptopoulou, C. P.; Terzis, A.; Bousseksou, A.; Tangoulis, V.; Tuchagues, J.-P.; Perlepes, S. P., Novel Rectangular [Fe4 $(\mu 4-\mathrm{OHO})(\mu-\mathrm{OH}) 2] 7+$ versus "Butterfly" [Fe4( $\mu 3-\mathrm{O}) 2] 8+$ Core Topology in the FeIII/RCO2-/phen Reaction Systems $(\mathrm{R}=\mathrm{Me}, \mathrm{Ph}$; phen $=1,10$-Phenanthroline $)$ : Preparation and Properties of [Fe4(OHO) $(\mathrm{OH}) 2(\mathrm{O} 2 \mathrm{CMe}) 4($ phen $) 4](\mathrm{ClO} 4) 3$,

[Fe4O2(O2CPh)7(phen)2](ClO4), and [Fe4O2(O2CPh)8(phen)2]. Inorg. Chem. 2002, 41, 6474-6487. (d) Castro, S. L.; Sun, Z.; Grant, C. M.; Bollinger, J. C.; Hendrickson, D. N.; Christou, G., SingleMolecule Magnets: Tetranuclear Vanadium(III) Complexes with a Butterfly Structure and an $\mathrm{S}=3$ Ground State. J. Am. Chem. Soc. 1998, 120, 2365-2375. (e) Liu, Q.; Yang, Y.; Huang, L.; Wu, D.; Kang, B.; Chen, C.; Deng, Y.; Lu, J., Study on an Assembly System Including Tetrathiovanadate. Syntheses and Structural Characterizations of V2Cu2S4 Cubane-Like Clusters and VS4Cu4 Bimetallic Aggregates. Inorg. Chem. 1995, 34, 1884-1893. (f) Sunatsuki, Y.; Shimada, H.; Matsuo, T.; Nakamura, M.; Kai, F.; 
Matsumoto, N.; Re, N., Synthesis, Magnetic Properties, and Incomplete Double-Cubane Structure of Manganese(III)-Metal(II) Complexes $[\mathrm{Mn}(\mathrm{MeOH}) \mathrm{L}(\mathrm{OH}) \mathrm{M}($ bpy $)] 2(\mathrm{M}=\mathrm{Zn}, \mathrm{Cu}, \mathrm{Ni}$, and $\mathrm{Mn}$; $\mathrm{H} 4 \mathrm{~L}=1,2$-Bis(2-hydroxybenzamido)benzene; bpy $=2,2^{6}$ Bipyridine). Inorg. Chem. 1998, 37, 5566-5574. (g) Papatriantafyllopoulou, C.; Abboud, K. A.; Christou, G., Carboxylate-Free MnIII2LnIII2 (Ln = Lanthanide) and MnIII2YIII2 Complexes from the Use of (2-Hydroxymethyl)pyridine: Analysis of Spin Frustration Effects. Inorg. Chem. 2011, 50, 8959-8966.

7. Vincent, J. B.; Chang, H. R.; Folting, K.; Huffman, J. C.; Christou, G.; Hendrickson, D. N., Preparation and physical properties of trinuclear oxo-centered manganese complexes of general formulation $[\mathrm{Mn} 3 \mathrm{O}(\mathrm{O} 2 \mathrm{CR}) 6 \mathrm{~L} 3] 0,+(\mathrm{R}=$ methyl or phenyl; $\mathrm{L}=\mathrm{a}$ neutral donor group) and the crystal structures of [Mn3O(O2CMe)6(pyr)3](pyr) and [Mn3O(O2CPh)6(pyr)2(H2O)].cntdot.0.5MeCN. J. Am. Chem. Soc. 1987, 109, 5703-5711.

8. Sheldrick, G., A short history of SHELX. Acta Crystallogr. Sect. A 2008, 64, 112-122.

9. Sheldrick, G. M., SHELXL-97, Programs for X-ray Crystal Structure Refinement; 1997, University of Göttingen: Göttingen, Germany, .

10. Barbour, L. J., J. Supramol. Chem. 2001, 1, 189-191.

11. Bencini, A.; Totti, F., DFT description of the magnetic structure of polynuclear transition-metal clusters: The complexes $[\{\mathrm{Cu}($ bpca $) 2(\mathrm{H} 2 \mathrm{O}) 2\}\{\mathrm{Cu}(\mathrm{NO} 3) 2\} 2], \quad$ (bpca $=\operatorname{Bis}(2-$ pyridylcarbonyl)amine), and $[\mathrm{Cu}(\mathrm{DBSQ})(\mathrm{C} 2 \mathrm{H} 5 \mathrm{O})] 2,(\mathrm{DBSQ}=3,5-$ di-tert-butyl-semiquinonato). Int. J. Quantum Chem. 2005, 101, 819825 .

12. Noodleman, L., Valence bond description of antiferromagnetic coupling in transition metal dimers. J. Am. Chem. Soc. 1981, 74, 5737-5743.

13. (a) Christian, P.; Rajaraman, G.; Harrison, A.; Helliwell, M.; McDouall, J. J. W.; Raftery, J.; Winpenny, R. E. P., Synthesis and studies of a trinuclear Mn(ii) carboxylate complex. Dalton Trans. 2004, 2550-2555. (b) Rajaraman, G.; Cano, J.; Brechin, E. K.; McInnes, E. J. L., Density functional calculations of a tetradecametallic iron(iii) cluster with a very large spin ground state. Chem. Commun. 2004, 1476-1477. (c) Ruiz, E.; Rodríguez-Fortea, A.; Cano, J.; Alvarez, S.; Alemany, P., About the calculation of exchange coupling constants in polynuclear transition metal complexes. J. Comput. Chem. 2003, 24, 982-989. (d) Baker, M. L.; Timco, G. A.; Piligkos, S.; Mathieson, J. S.; Mutka, H.; Tuna, F.; Kozlowski, P.; Antkowiak, M.; Guidi, T.; Gupta, T.; Rath, H.; Woolfson, R. J.; Kamieniarz, G.; Pritchard, R. G.; Weihe, H.; Cronin, L.; Rajaraman, G.; Collison, D.; McInnes, E. J. L.; Winpenny, R. E. P., A classification of spin frustration in molecular magnets from a physical study of large odd-numbered-metal, odd electron rings. Proc. Natl. Acad. Sci. USA 2012, 109, 19113-19118. (e) Christian, P.; Rajaraman, G.; Harrison, A.; McDouall, J. J. W.; Raftery, J. T.; Winpenny, R. E. P., Structural, magnetic and DFT studies of a hydroxide-bridged $\{\mathrm{Cr} 8\}$ wheel. Dalton Trans. 2004, 1511-1512. (f) Cremades, E.; Cano, J.; Ruiz, E.; Rajaraman, G.; Milios, C. J.; Brechin, E. K., Theoretical Methods Enlighten Magnetic Properties of a Family of $\mathrm{Mn}_{6}$ Single-Molecule Magnets. Inorg. Chem. 2009, 48, 8012-8019. (g) Vignesh, K. R.; Langley, S. K.; Moubaraki, B.; Murray, K. S.; Rajaraman, G., Large Hexadecametallic $\left\{\mathrm{Mn}^{\mathrm{III}}-\mathrm{Ln}^{\mathrm{III}}\right\}$ Wheels: Synthesis, Structural, Magnetic, and Theoretical Characterization. Chem. Eur. J. 2015, 21, 16364-16369. (h) Vignesh, K. R.; Langley, S. K.; Murray, K. S.; Rajaraman, G., What Controls the Magnetic Exchange Interaction in Mixed- and Homo-Valent $\mathrm{Mn}_{7}$
Disc-Like Clusters? A Theoretical Perspective. Chem. Eur. J. 2015, 21, 2881-2892.

14. Becke, A. D., Density functional thermochemistry. III. The role of exact exchange. J. Chem. Phys. 1993, 98, 5648-5652.

15. (a) Schaefer, A.; Horn, H.; Ahlrichs, R., Fully optimized contracted Gaussian basis sets for atoms Li to Kr. J. Chem. Phys. 1992, 97, 2571-2577. (b) Schaefer, A.; Huber, C.; Ahlrichs, R., Fully optimized contracted Gaussian basis sets of triple zeta valence quality for atoms Li to Kr. J. Chem. Phys. 1994, 100, 5829-5835.

16. Gaussian 09, R. A.02, Frisch, M. J. ; G. W. Trucks; H. B. Schlegel; G. E. Scuseria; M. A. Robb; J. R. Cheeseman; G. Scalmani; V. Barone; B. Mennucci; G. A. Petersson; H. Nakatsuji; M. Caricato; X. Li; H. P. Hratchian; A. F. Izmaylov; J. Bloino; G. Zheng; J. L. Sonnenberg; M. Hada; M. Ehara; K. Toyota; R. Fukuda; J. Hasegawa; M. Ishida; T. Nakajima; Y. Honda; O. Kitao; H. Nakai; T. Vreven; J. A. Montgomery; Jr., J. E. P.; F. Ogliaro; M. Bearpark; J. J. Heyd; E. Brothers; K. N. Kudin; V. N. Staroverov; R. Kobayashi; J. Normand; K. Raghavachari; A. Rendell; J. C. Burant; S. S. Iyengar; J. Tomasi; M. Cossi; N. Rega; J. M. Millam; M. Klene; J. E. Knox; J. B. Cross; V. Bakken; C. Adamo; J. Jaramillo; R. Gomperts; R. E. Stratmann; O. Yazyev; A. J. Austin; R. Cammi; C. Pomelli; J. W. Ochterski; R. L. Martin; K. Morokuma; V. G. Zakrzewski; G. A. Voth; P. Salvador; J. J. Dannenberg; S. Dapprich; A. D. Daniels; Ö. Farkas; J. B. Foresman; J. V. Ortiz; J. Cioslowski, a.; D. J. Fox; Gaussian, I., Wallingford CT . 2009.

17. Chilton, N. F.; Anderson, R. P.; Turner, L. D.; Soncini, A.; Murray, K. S., PHI: A powerful new program for the analysis of anisotropic monomeric and exchange-coupled polynuclear d- and fblock complexes. J. Comput. Chem. 2013, 34, 1164-1175.

18. Neese, F., The ORCA program system. WIREs Comput. Mol. Sci. 2012, 2, 73-78.

19. (a) Berg, N.; Hooper, T. N.; Liu, J.; Beedle, C. C.; Singh, S. K.; Rajaraman, G.; Piligkos, S.; Hill, S.; Brechin, E. K.; Jones, L. F., Synthetic, structural, spectroscopic and theoretical study of a $\mathrm{Mn}$ (iii)-Cu(ii) dimer containing a Jahn-Teller compressed Mn ion. Dalton Trans. 2013, 42, 207-216. (b) Singh, S. K., gupta T., Padku P., Rajaraman G., Magnetic Anisotropy of Mononuclear NiII Complexes: On the Importance of Structural Diversity and the Structural Distortions. Chem. Eur. J. 2014, 20, 10305-10313. (c) Singh, S. K.; Rajaraman, G., Probing the Origin of Magnetic Anisotropy in a Dinuclear $\{\mathrm{MnIIICuII}\}$ Single-Molecule Magnet: The Role of Exchange Anisotropy. Chem. Eur. J. 2014, 20, 52145218. (d) Singh, S. K.; Rajaraman, G., Can anisotropic exchange be reliably calculated using density functional methods? a case study on trinuclear MnIII-MIII-Mn III ( $\mathrm{M}=\mathrm{Fe}, \mathrm{Ru}$, and $\mathrm{Os}$ ) cyanometalate single-molecule magnets. Chem. Eur. J. 2014, 20, 113-123. (e) Sinnecker, S.; Neese, F.; Noodleman, L.; Lubitz, W., Calculating the Electron Paramagnetic Resonance Parameters of Exchange Coupled Transition Metal Complexes Using Broken Symmetry Density Functional Theory:â€\%o Application to a MnIII/MnIV Model Compound. J. Am. Chem. Soc. 2004, 126, 2613-2622.

20. (a) Langley, S. K.; Chilton, N. F.; Ungur, L.; Moubaraki, B.; Chibotaru, L. F.; Murray, K. S., Heterometallic Tetranuclear $\left[\mathrm{Ln}^{\mathrm{III}}{ }_{2} \mathrm{Co}^{\mathrm{III}}{ }_{2}\right]$ Complexes Including Suppression of Quantum Tunneling of Magnetization in the $\left[\mathrm{Dy}^{\mathrm{III} 2} \mathrm{Co}^{\mathrm{III} 2}\right]$ Single Molecule Magnet. Inorg. Chem. 2012, 51, 11873-11881. (b) Langley, S. K.; Moubaraki, B.; Murray, K. S., A heptadecanuclear $\mathrm{Mn}^{\mathrm{III}} \mathrm{Dy}^{\mathrm{III}}$ cluster derived from triethanolamine with two edge sharing supertetrahedra as the core and displaying SMM behaviour. Dalton Trans. 2010, 39, 5066-5069. (c) Langley, S. K.; Ungur, L.; Chilton, N. F.; Moubaraki, B.; Chibotaru, L. F.; Murray, K. S., SingleMolecule Magnetism in a Family of $\left\{\mathrm{Co}^{\mathrm{III}} \mathrm{Dy}^{\mathrm{III}}\right\}$ Butterfly 
Complexes: Effects of Ligand Replacement on the Dynamics of Magnetic Relaxation. Inorg. Chem. 2014, 53, 4303-4315.

21. Liu, W.; Thorp, H. H., Bond valence sum analysis of metal-ligand bond lengths in metalloenzymes and model complexes. 2. Refined distances and other enzymes. Inorg. Chem. 1993, 32, 4102-4105.

22. Berg, N.; Rajeshkumar, T.; Taylor, S. M.; Brechin, E. K.; Rajaraman, G.; Jones, L. F., What Controls the Magnetic Interaction in bis- $\mu$-Alkoxo $\mathrm{Mn}^{\mathrm{III}}$ Dimers? A Combined Experimental and Theoretical Exploration. Chem. Eur. J. 2012, 18, 5906-5918.

23. (a) Singh, S. K.; Gupta, T.; Rajaraman, G., Magnetic Anisotropy and Mechanism of Magnetic Relaxation in Er(III) SingleIon Magnets. Inorg. Chem. 2014, 53, 10835-10845. (b) Singh, S. K.;
Gupta, T.; Shanmugam, M.; Rajaraman, G., Unprecedented magnetic relaxation via the fourth excited state in low-coordinate lanthanide single-ion magnets: a theoretical perspective. Chem. Commun. 2014, 50, 15513-15516. (c) Singh, S. K.; Gupta, T.; Ungur, L.; Rajaraman, G., Magnetic Relaxation in Single-Electron Single-Ion Cerium(III) Magnets: Insights from Ab Initio Calculations. Chem. Eur. J. 2015, 21, 13812-13819.

24. Cauchy, T.; Ruiz, E.; Alvarez, S., Magnetostructural Correlations in Polynuclear Complexes: The Fe4 Butterflies. J. Am. Chem. Soc. 2006, 128, 15722-15727.

\section{Table of contents}

\section{What Controls the Magnetic Exchange and Anisotropy in a Family of Tetranuclear $\left\{\mathrm{Mn}_{2}{ }^{\mathrm{II}} \mathrm{Mn}_{2}{ }^{\mathrm{III}}\right\}$ Single Molecule Magnets?}

Kuduva R. Vignesh, ${ }^{\dagger}$ Stuart K. Langley, ${ }^{!}$Christopher J Gartshore, ${ }^{\star}$ Boujemaa Moubaraki, ${ }^{*}$ Keith S. Murray, ${ }^{*} \star$ and Gopalan Rajaraman ${ }^{*} \S$

$\dagger$ IITB-Monash Research Academy, IIT Bombay, Mumbai-400076, India. I School of Chemistry, Monash University, Clayton, Victoria-3800, Australia.

! School of Science and the Environment, Chemistry Division, Manchester Metropolitan University, Manchester, UK.

$\S$ Department of Chemistry, Indian Institute of Technology Bombay, Mumbai-400076, India.

\section{Table of contents}

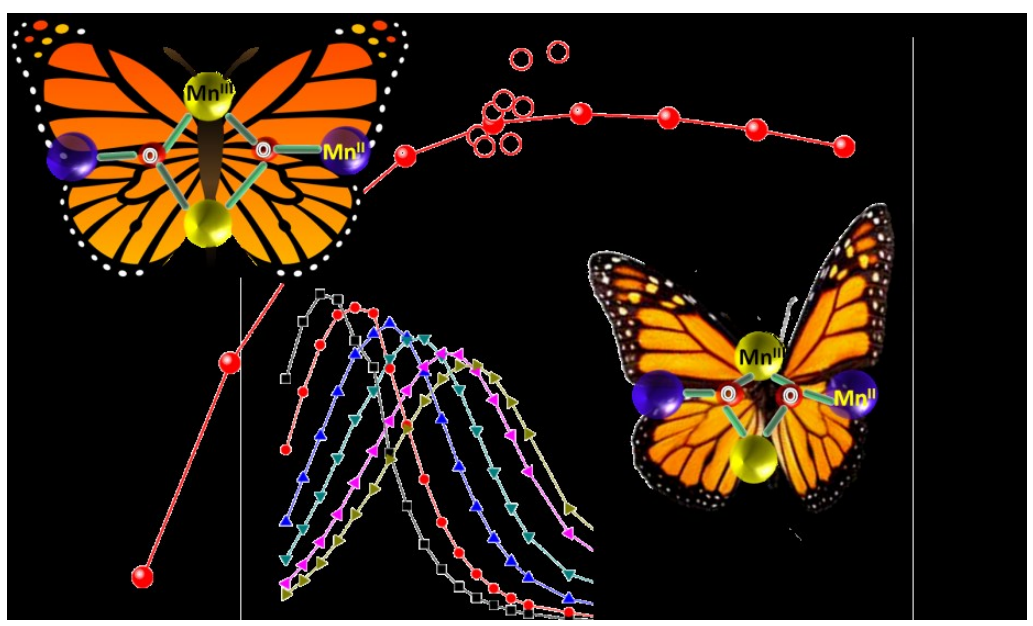

A combined experimental and theoretical study on a series of $\left\{\mathrm{Mn}^{\mathrm{II} / \mathrm{III}} 4\right\}$ "butterfly" complexes unveils ways to synthesize targeted $\left\{\mathrm{Mn}^{\mathrm{II} / \mathrm{III}} 4\right\}$ SMMs. 